\title{
EXPLORING THE IMPORTANCE OF EMPLOYEE INCENTIVES AND THEIR EFFECTIVENESS IN IMPROVING QUALITY PERFORMANCE IN A CAMBODIAN PUBLIC ORGANIZATION
}

OUN TEP

\begin{abstract}
A Thesis
submitted to Victoria University of Wellington

in partial fulfillment of the requirement for the degree of Master of Management Studies
\end{abstract}

Victoria University of Wellington

2015 


\section{ACKNOWLEDGEMENTS}

Personally, undertaking a Master's degree by thesis is a very long journey with many challenges to face. Even though it sounds a bit hard and incredible those difficulties will gradually subside with the cheerful moment of the fulfillment of all the school's requirements and finally reaching my goal - a Master's Degree. I do acknowledge that without some important people who made tremendous contributions and sacrifices huge amounts of time and effort with countless support, I might not be able to survive and sustain such difficult circumstances. Therefore, there are several people that I would like to acknowledge and thank for their enormous contribution and support.

First of all, I would like to express my gratitude to my thesis supervisor Prof Lawrence Corbett at the School of Management, Victoria University of Wellington. He provided unique guidance and supervision in the field of management, he shaped my research ideas, and pointed me toward new angles on current topics, and finally we came up with a meaningful and successful research proposal. This does not include the regular support, supervision and comments on every small piece of my thesis for the whole year, which was always helpful and encouraging. And thanks to all management and staff at the School of Management, Victoria University of Wellington, for their assistance and cooperation during my academic years.

I must thank NZAID particularly the management and teams of the NZAID programme for their ongoing support and cooperation. I acknowledge that both the technical and financial assistance from the NZAID programme were extremely important for me to pursue my advanced education - a Master's Degree in New Zealand.

An additional special thanks to all research participants, management and staff of the Cambodian Investment Board - CIB under the Council for the Development of Cambodia - CDC for their participation, contribution and cooperation to make this research happen. Furthermore, I would like to thank all my close friends, friends, and landlords for support and sometimes making jokes to cheer me up whenever I was upset and worried. 
Finally, I would like to express my true gratitude to my family - especially my parents for providing their multi-faceted support and continuous encouragement of my academic work, with patience unlimited and unending help in every aspect of my life. They were always a great source of motivation in accomplishing this academic goal. 


\begin{abstract}
The main purpose of this study is to identify the importance of incentives and their effectiveness in employee performance. The detail of this research will be conducted in an attempt to demonstrate whether incentives have a great potential to increase public employees' motivation and work performance. The purpose of the research is also to illustrate to what extent incentives are used in the Cambodian public service sector. To fulfill the objective of the research as well as to obtain real and reliable data, a research study was conducted at the Cambodian Investment Board - CIB under the Council for the Development of Cambodia - CDC.
\end{abstract}

The method of this research study was implemented with a qualitative analysis to investigate the work characteristic of Cambodian public employees, and to identify the correlation between the rewarding, recognition and employee work performance. In addition to the research method, the analysis of the qualitative interview data was to be done through the use of thematic analysis. After the qualitative research method was completely finished, the findings of the research study were much the same as those mentioned in the literature review. The data analysis proved a significant correlation between incentives in the form of rewards and recognition, and better work performance.

Based on the findings of this research study, most of the public employees in the above mentioned organization commented that both financial and non-financial incentives are significantly important to encourage and motivate them for greater work performance. It also indicated that there was an absence of employee incentive particularly financial incentive. Meanwhile, the level of utilization of non-financial incentives is extremely poor. Therefore, within the limitations of the research study, it could be concluded that both financial and non-financial incentives have a potential effect on employee motivation and work performance in the public service organization of Cambodia. 


\section{EXECUTIVE SUMMARY}

All organizations whether profit oriented, non-profit oriented or public service organizations, need to motivate their employees to be more effective and efficient in their operation. It is believed that motivating employees to work energetically and successfully toward the achievement of the organizational objective is one of the key components to the success of the organization. In the context of employee motivation, incentives have been used as motivational tools for encouraging and motivating employees to exert extra effort, and to improve employee work performance and productivity. Thus, incentives are playing a key role in motivating employees. It also believed that public service sectors differ from the private sector, but how they differ and to what level they differ are still debated among researchers and practitioners.

Research around employee motivation has been frequently and successfully explored among researchers, scholars and employers. As a result, an abundance of theoretical and practical approaches have been created in an attempt to explore and explain the nature of employee motivation, the implementation and its effect on the organizations. However, those research studies were mostly conducted in the private sector and less attention has been paid to the public service sector particularly the public organizations of Cambodia. With these shortfalls, it is difficult for public leaders to get to know the perception of public employees as well as the job characteristic of public organization. Understanding the potential effect of public employee motivation would enable public leaders to develop incentives more effectively and thereby implement those incentives as motivational tools for job satisfaction and ultimately performance.

The primary purpose of this research study is to explore the importance of employee incentives and their effectiveness in improving the performance of employees in a Cambodian public organization. The method that was used to reach the objective of this research was qualitative research analysis by interviewing eight research participants from the Cambodian Investment Board - CIB under the Council for the Development of Cambodia-CDC. The research study first investigated the characteristics of incentives, the types of incentives, their importance and their effect 
on employee motivation. At this stage, theoretically based definitions and conceptualizations of incentives as well as employee motivation were identified and explained in order to better understand this research construct. Next, the correlation between employee motivation and job satisfaction was identified, and finally their effect on the employee performance and organization productivity as a whole.

The findings of this research study revealed that incentives are extremely important in encouraging and motivating Cambodian public employees to work harder, to perform better and effectively achieve organizational goals. The research findings also indicated that financial incentives are the most commonly required among other needs. In addition to these financial needs, most of the Cambodian public employees mentioned that direct financial benefit such as wage satisfaction is strongly required. Meanwhile, non-financial incentives are the second most valued among the public employees' responses. In the sense of non-financial incentives, job related support and organizational support are preferred as the incentives that would increase the public employees' interest in their work and workplace most. Specifically, this mean that most Cambodian public employees value meaningful jobs with more opportunities for promotion, more responsibility, more flexible working hours, a variety of tasks and opportunity to use a diversity of skills and knowledge. In this regard, it can be concluded that this public organization would benefit not only from financial incentives in the motivation of employees, but also from non-financial incentives. 


\section{TABLE OF CONTENTS}

\section{CHAPTER 1 INTRODUCTION}

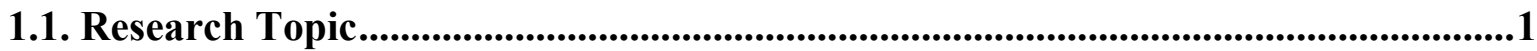

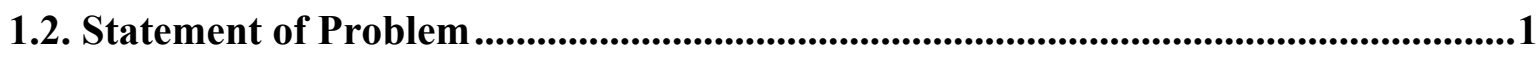

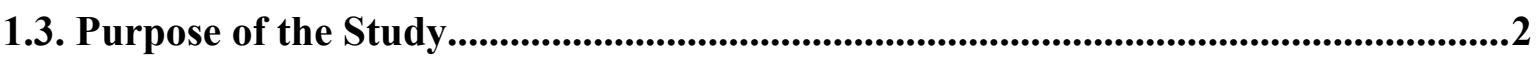

1.4. Overview of Cambodia Public Motivation .......................................................................3

1.5. Introduction ................................................................................................................................4

1.6. Organization of Study ...............................................................................................................6

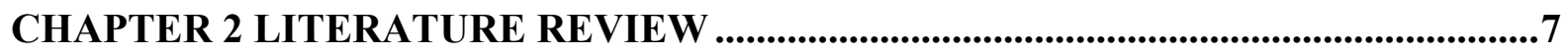

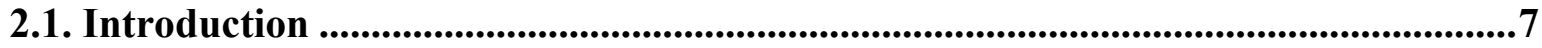

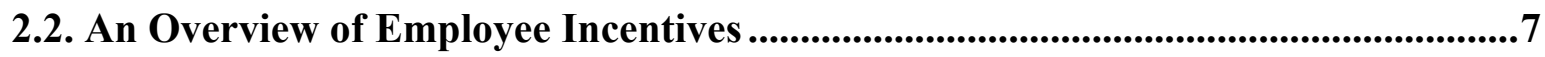

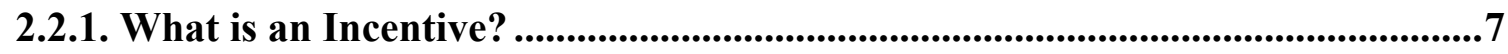

2.2.2. Type of Incentives .................................................................................................................9

2.2.2.1. Financial Incentives ........................................................................................10

2.2.2.2. Non-financial Incentives ..............................................................................................11

2.2.3. The Effect of Incentive in the Organization .....................................................13

2.2.3.1. The Positive Effect of Incentives ................................................................13

2.2.3.2. The Negative Effect of Incentives ..............................................................14

2.2.4. Incentives in Public Organization ............................................................15

2.2.5. Evidence on the Implementation of Incentives ......................................................15

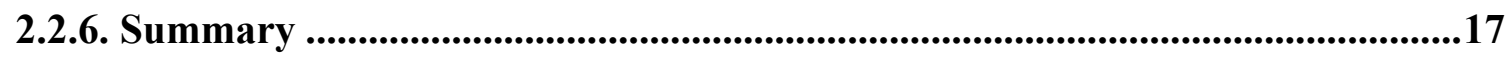

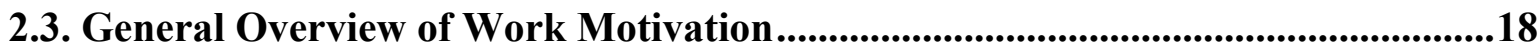

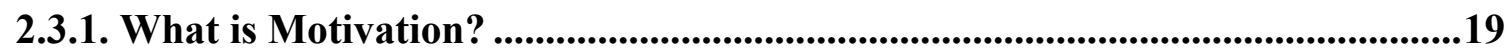

2.3.2. Variable Affecting the Motivation Process.........................................................21

2.3.3. Theories of Motivation ........................................................................................................224

2.3.3.1. Maslow's Hierarchy of Needs Theory ...................................................26

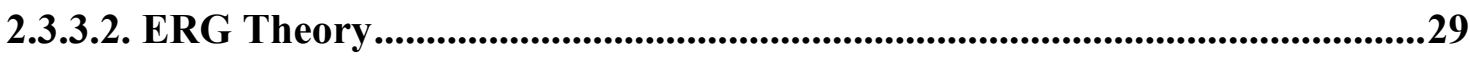

2.3.3.3. McClelland's Three Needs Theory …....................................................................30

2.3.3.4. Motivation-Hygiene Theory ......................................................................................31

2.3.3.5. Job Characteristic Theories ...................................................................................33

2.3.4. Intrinsic and Extrinsic Motivation ..................................................................33

2.3.5. The Effect of Motivation on Job Satisfaction................................................35 


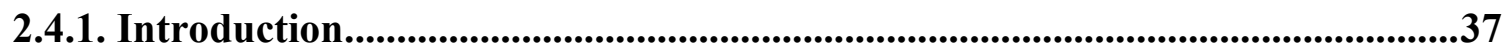

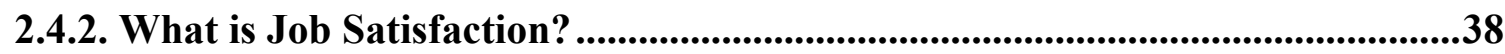

2.4.3. Determinants of Job Satisfaction .................................................................38

2.4.4. Theories of Job Satisfaction .......................................................................................39

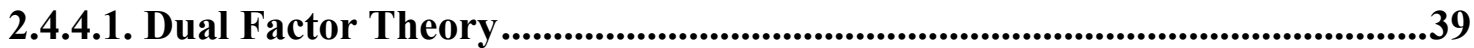

2.4.4.2. Equity Theory ..................................................................................................40

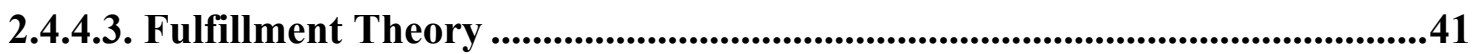

2.5. The Linkage Between Incentives, Job Satisfaction and Work

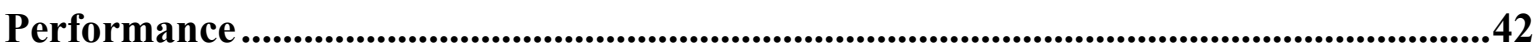

2.5.1. Casual Relationship and Outcome .................................................................................42

2.5.2. Diagram Show the Linkage Between Incentives, Job Satisfaction and

Work Performance ..............................................................................................................44

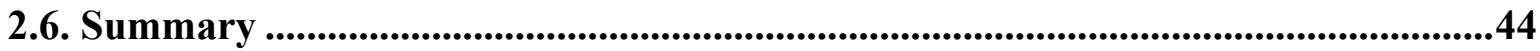

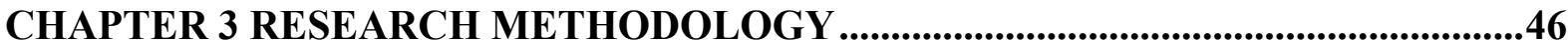

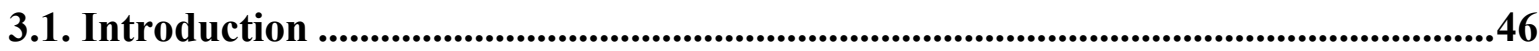

3.2. Quantitative and Qualitative Research ....................................................................47

3.3. Research Design .........................................................................................................................48

3.3.1. Choice of Selecting Organization ...................................................................................50

3.3.2. Data Collection ..........................................................................................................51

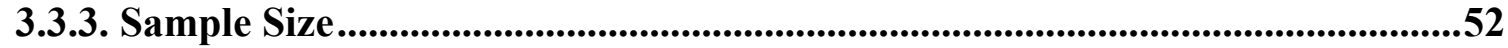

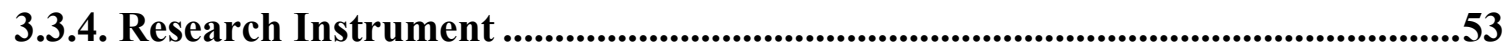

3.3.5. Interview Technique .............................................................................................54

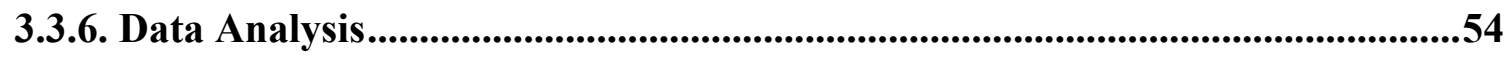

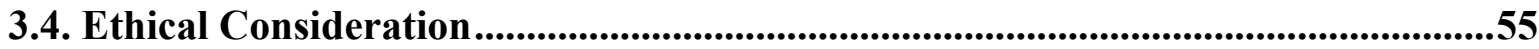

3.5. Foreseeable Limitation of Research..................................................................................56

CHAPTER 4 RESEARCH FINDINGS .....................................................................................57

4.1. Introduction .....................................................................................................................5

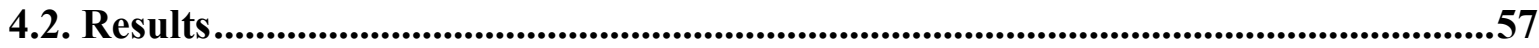

4.3. Summary of Research Findings ....................................................................

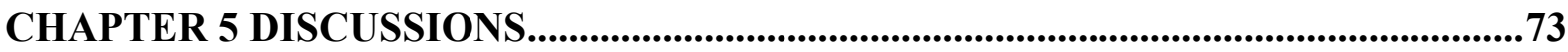

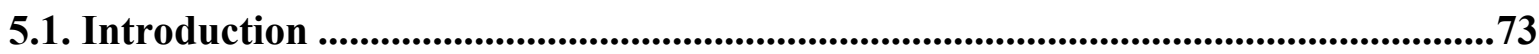

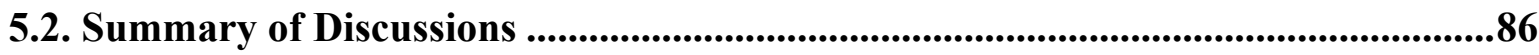




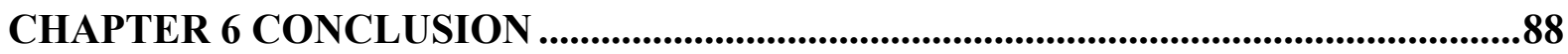

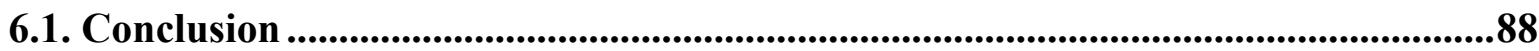

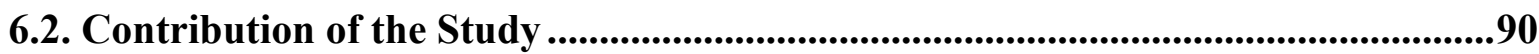

6.3. Implications for Public Sector Management...........................................................91

6.4. Limitations and Future Research Direction .......................................................92

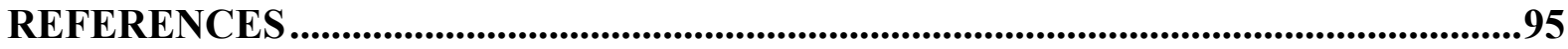

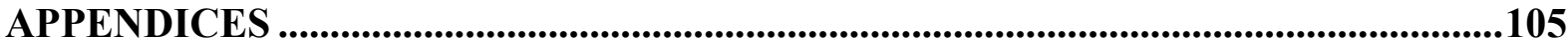

Appendix A Organization Letter of Permission ..............................................................105

Appendix B Research Project Information Sheet ..........................................................106

Appendix C Research Project Consent Form ............................................................108

Appendix D Indicative Research Questions ..............................................................109 


\section{CHAPTER 1 \\ INTRODUCTION}

\subsection{RESEARCH TOPIC}

Exploring the importance of employee incentives and their effectiveness in improving quality performance in a Cambodian public organization.

\subsection{STATEMENT OF THE PROBLEM}

Psychological research has been conducted concerning employee motivation within organizations. Some argue that incentives are the most important motivators (Epley \& Gilovich, 2005; Shanks, Tunney \& McCarthy, 2002; Stone \& Ziebart, 1995). According to the survey conducted by World at Work (2007), 70 percent of compensation professionals are important or very important to the sustainability and success of the organizations. Similarly, Rydval and Ortmann (2001, p.7) also supported the reason to be more optimistic about the effects of incentives, they also concluded that, "In the majority of cases where payment made a difference, they improved people's performance". In human resource management, incentive is also a useful mechanism to identify and attract the most qualified staff and motivate them to exert more effort at their job. Such kinds of implementation have shown that staff who are paid incentives have significantly increased productivity (Cadsby, Song \& Tapon, 2007).

Research around employee motivation has been frequently and successfully conducted among researchers, scholars and practitioners (Culpepper, 2009; Cadsby, Song \& Tapon, 2007; Epley \& Gilovich, 2005; Shanks, Tunney \& McCarthy, 2002; Rydval \& Ortmann, 2001; Stone \& Ziebart, 1995). As a result, an abundance of theoretical and practical approaches were created in an attempt to explore and explain the nature of employee motivation, the implementation and their effect on the organizations. However, those research studies were mostly conducted in the private sector.

Some research however has been conducted around the effect of employee incentives in the public organizations (Glazer, 2004; Besley \& Ghatak, 2003; Prendergast, 2003; Dixit, 2002; Delfgaauw \& Dur, 2002; Francois, 2000; Heckman; Cragg, 1997; Courty \& Marschke, 1997; Smith \& Taber, 1996; Andersom, Burkhauser \& 
Raymond, 1993), but those studies are mainly conducted in the international context and some are conducted in industrialized countries where social, economical and cultural factors are different. Therefore, they might not be applicable in some developing countries, particularly in the context of Cambodia. With these shortfalls, it is difficult for Cambodian public leaders to get to know the perception of public employees as well as the job characteristics of public organizations. Understanding the potential effect of public employee motivation would enable Cambodian public organizations to understand and develop incentives more effectively and thereby implement those incentives as potential motivational tools for job satisfaction and ultimately performance.

\subsection{PURPOSE OF THE STUDY:}

This study is going to explore the importance of employee incentives and their effectiveness in improving quality performance in the context of Cambodian public organizations. This research study will be conducted by choosing the Cambodian Investment Board - CIB under the Council for the Development of Cambodia as a case study. Furthermore, in order to reach the main purpose of this study, we are going to answer some questions as follow:

- What does the general concept of incentives mean to employees in the Cambodian public organization?

- What are the effects of incentives on the outcome of an organization?

- What type of incentive is most suitable to use in public organizations especially in the Cambodian context?

- To what extend do incentives have a potential motivation for the employee in the public organization?

- How do public employees perceive the overall organizational performance in the absence of incentives?

There might be infrequent use or no use of incentives in some less developed countries especially in Cambodia. An alternative view of Burgess and Ratto (2003) is that the relative weakness of an incentive scheme in the public sector is due to strong union opposition and weak government. 
Therefore, the aim of this study is to identify the importance of public employee incentives and factors affecting their work performance within the Cambodian public organization. If such factors are identified, institutional changes can be made to enhance the internal working environment, promote higher levels of job satisfaction, solve organizational problems and consequently, improve the level of work performance and lastly to increase organizational productivity. In addition, we will investigate the reasons for the absence of an incentive scheme in the public sector and outline some positive and negative aspects of using those incentives within a public organization.

\subsection{OVERVIEW OF CAMBODIAN PUBLIC MOTIVATION}

In the context of Cambodia, financial incentives or direct financial benefits such as salaries represent a major challenge for public organizations, since these are too low to attract, and encourage public employees to work harder. Even though most Cambodian public employees seem to enjoy job stability and security they obtain only fixed wage levels regardless of their performance; there are no incentives such as a performance based pay system compared to the private sector.

Beside the development and implementation of financial incentives in the Cambodian public organizations, there is no guarantee that financial incentives alone will be enough to motivate public employees. It is commonly understood that individuals have a variety of needs such as the need for recognition, respect and approval from superiors as well as from co-workers, a need for work autonomy, flexible working hours, self development and advancement and so on. All of these factors suggest that non-financial incentives may be a necessary source of motivation for public organizations to use. However, those non-financial incentives have been underestimated by a majority of public organizations in Cambodia.

Therefore, it is important particularly for the public service sector, that some kind of incentive mechanism should be developed in order to encourage good performance of employees, to recognize their contributions and promote a better working environment within the organization. In the sense of developing an incentives 
mechanism within the Cambodian public organizations, there are three options to be considered: financial incentives, non-financial incentives or both.

\subsection{INTRODUCTION}

It is widely recognized that human resources are one of the key assets of an organization because most things are performed and achieved by people. To put it simply, the success of an organization greatly relies on the performance of its employees. And finding the possible and effective ways to encourage people to exert extra effort beyond what is normally required among the employers and business researchers. Therefore, not only should those organizations prepare the best strategy to improve their existing performance, but each organization should also come up with the best way to recruit qualified staff, and to retain and to motivate their employees at the highest level so that the organization as a whole can perform well within their operational environment. In this regard, all organizations, whether profit oriented or non-profit oriented, need to motivate their employees in order to be effective and efficient in their operation. Locke and Latham (2004) argued that even though the theories of work motivation exist and shed some light on employee motivation, they all have some limitations, and thus, our understanding and knowledge of what motivates employees is still very much incomplete. Thus, understanding what motivates employees to work near or at the highest level is a critical issue for all organizations.

While talking about motivation, one of the prominent ideas that comes to one's mind is the concept of incentives, which refers to any things that push or encourage employees to work harder and to perform better in order to achieve certain goals. It also believed that employees who are highly motivated would work energetically, effectively and successfully toward the achievement of organizational goals. According to this, the effectiveness of incentives as well as the correlation between incentives and quality of work performance in the organizations are well addressed in many studies and academic research (Boyle, 2007; Cadsby, Song \& Tapon, 2007).

On the other hand, an incentives system that works in one country might not be applicable in another country. Similar findings have been supported by Chiang and Birtch (2005). Incentive systems are different from country to country and these 
differences may have social, economic, political or cultural causes. For instance, the implementation of incentives systems is different between Dutch and American organizations. There are many reasons behind those differences and globalization might be one reason for the increase in incentive systems.

In the past, performance compensation remained relatively unchanged while the world around was completely changed. Based on the study of Heery (1996), these key fundamental changes started in the beginning of 1980's, led by the American motor industry giants who had seen their market share dramatically reduced by Japanese quality, reliability and price advantage. The motor industry in America then began a lengthy competition toward efficiency, quality, price and customer orientation, causing its employees successive traumas of re-engineering, restructuring, revitalization and redundancy.

According to the study conducted by PWC (2008) as a result of leaders who need their subordinate staff to make an extra effort and increase their productivity, an incentive system has been increasingly popular in Sweden. The evolution of the concept of human resource management in the minds of organizational leaders led to the recognition that the workforce was one of the key success factors in a strong, competitive environment (Heery, 1996). Beginning from that, the way employees are selected, recruited, trained, challenged and involved has become an essential component in organizational success and sustainability. In each of these components, the employee incentive issue needs to play an important role in producing a wellequipped, high achieving, hard working people, focused on organizational goals.

It is believed that an employee's behavior is influenced by the different types of incentives. Therefore, for the purpose of rewarding as well as recognizing greater performance, incentives are the key tool in regard to employee motivation. Apart from those, it would depend on the organization to determine what type of incentives are needed for their specific situation (Lawler, 1996). Organizational value and culture are also important in determining the success of employee incentives. It is not always about the money, it can be a symbol of what an organization believes is valuable (Lawler \& Jenkins, 1992; Ledford \& Lawler, 1994; McAdams, 1996, Lawler, 2000). 
A good understanding of the way in which an organization functions requires that at least some attention be organized and led toward the question of why people within the organization behave as they do on the job, and the ramifications of such behaviour for an organization. In this regard, a comprehensive understanding of the topic of employee incentives is crucial in order to comprehend more fully the effects of variation in other organizational factors particularly the pay system, employee recognition, organizational culture, management and leadership behavior, which are related to job satisfaction and work performance.

\subsection{ORGANIZATION OF STUDY}

This study will be organized into six chapters. Chapter one, the introduction, will start with a general overview of Cambodian public organizations, give the statement of problems, and purposes of the study including research questions. The next chapter is chapter two which will provide an overview of incentives, a typology of incentives with specific attention to the distinction between financial and nonfinancial incentives. In addition, some definitions of key terms, concepts, examples, theoretical and practical studies of employee incentives of other countries will be included to support the review of literature. Since incentives have been used as motivational tools the detailed review of motivation is mentioned in line with theories of motivation and job satisfaction. The correlation between incentives, motivation and job satisfaction has laid a strong foundation and will be the basis for the discussion through the entire study. Chapter three is going to describe the methodology used for this research study, which includes the research design, nature of research participants, data collection process, data interpretation, ethical considerations, and limitations. Chapter four will discuss research findings. Chapter five provides discussion, which will be developed by interpreting the research findings and supported by the review of literature as stated in Chapter two. Chapter six, providing conclusions will include contributions of the study, implications for public sector management, limitations and future research directions. 


\section{CHAPTER 2 \\ LITERATURE REVIEW}

\subsection{INTRODUCTION}

This chapter will mainly discuss the three variables at hand. First, I am going to discuss incentives in general and more specifically the typical incentives: financial incentive and non-financial incentives. Since incentives will be used as a motivational tool to encourage employees to make an extra effort to achieve their goal thus we are going to briefly discuss and explain the concept of motivation in general followed by Maslow's hierarchy of needs and other related theories. This section will seek to cover literature related to the research objective. It aims to create a sufficient link with the main objective, which is to identify whether there is a significant correlation between employee incentives and quality of work performance within a public organization. The next section will define job satisfaction followed by the discussion of different aspects of job satisfaction, the theories around the facets of job satisfaction as well as the correlation between job satisfaction and work performances. The discussion of job satisfaction will broadly consider its consequences, both the positive and negative effects of job satisfaction on individuals, groups and the entire organizational performance.

\subsection{AN OVERVIEW OF EMPLOYEE INCENTIVES}

\subsubsection{WHAT IS AN INCENTIVE?}

Incentives have been defined and used in different areas. In the context of the health care industry, incentives are defined as "An available means apply with intention to influence the willingness of physicians and nurses to exert and maintain an effort toward attaining organizational goals" (Mathauer \& Imhoff, 2006). Based on the World Health Report 2000, the definition of incentive in the health care industry is generally about "all the rewards and punishments that providers face as a consequence of the organizations in which they work, the institutions under which they operate and the specific interventions they provide" (Adam \& Hicks, 2000). This defining primary places on individual, in the context of service provider, within a specific organization and acknowledges the importance of the wider institutional context as well as the particular work implemented by the individual or group will determine the incentives used and its outcome. In this sense, incentives are 
considered as factors within health care work environments that enable, encourage and motivate staff to stick with their careers, in their profession and within their national boundary.

In the context of education, incentives are used to encourage students to increase their work effort and study performance. According to a UNDP Capacity Development Resource (2006, p.12), “incentives are external measures that are designed and established to influence motivation and behavior of individuals, groups or organizations". Whereas, in the tourism sector, incentive has been defined differently. According to a study from the Society of Incentive and Travel Executive (SITE), Incentive is a "management tool that uses an exceptional travel experience to motivate and/or recognize participants or increase level of performance in support of organizational tools". It is a kind of compensation that has been designed to recognize employee's performance and their accomplishment.

Meanwhile, from organizational standpoints, incentive is defined as a technique, which is usually used by employers to carry out their end of the employment contract, a form of compensation to the employees for their effort (Hartman, Kurtz \& Moser, 1994). Incentives are tangible or intangible rewards used to motivate a person or group of people to behave in a certain way (Collins, Tinkew \& Burkhauser, 2008). A similar definition is given by Zurn, Dolea and Stilwell (2005, p.5), incentive is "an explicit or implicit financial or non-financial reward for performing a particular act”. Meanwhile Banjoko (2006) generally regards incentive as variable payments, which are made to employees or a group of employees on the basis of the amount of output or based on the achieved result. Optionally, it can be the payment made with the aim of pushing employee daily work performance in an attempt to reach a common goal. Incentive could also be defined as compensation other than basic salaries or wages that usually fluctuates based on employee exceptional performance and their attainment of some standard set by the organization (Martocchio, 2006).

From the above discussion, incentive can be defined in different ways with different contexts and situations. However, the core concept of those definitions is around tangible or intangible compensation, explicit or implicit ways to influence 
individuals or groups of people to exert more time and effort in order to achieve personal as well as organizational goals.

\subsubsection{TYPES OF INCENTIVES}

There are different types of incentives. Buchan, Thompson and O'May (2000) expressed that incentive can be positive, negative (as in disincentives), financial or non-financial, tangible or intangible. Some authors separate incentives into three types: (1) monetary incentive, (2) non-monetary tangible incentive (coupons or vouchers for foods, vocation trip or others), and (3) non-monetary intangible (employee recognition, praise or appreciation on job accomplishment, positive evaluation and feedback, etc.) (Condly, Clark \& Stolovitch, 2003). Although there are significantly different types of incentives that could be utilized, a useful distinction between financial (monetary) and non-financial (non-monetary) incentive is commonly used. Financial incentives involve granting of financial reward such as bonuses, commission, pay increases or other benefits (De Cenzo et al, 1996; Buchan, Thompson \& O'May, 2000). Whereas, non-financial incentives do not involve any payments or benefits and it mostly relates to psychological and emotional fulfillment (Assaf, 1999; Bunchan, Thompson \& O’May, 2000). For instance, encouraging employees to participate in decision-making, providing more autonomy in their job, and improving their working environment, and so on.

The below table will briefly describe the different aspects of both financial and nonfinancial incentives.

Table 1: TYPES OF INCENTIVES

\begin{tabular}{|c|c|c|}
\hline 1 & Financial Incentives & $\begin{array}{l}\text { - } \text { Pay (Salary or others) } \\
\text { - } \text { Pensions, bonuses, insurance (accident, } \\
\text { - } \text { health, or life insurance, etc.) } \\
\text { - } \text { childowances (accommodation, clothing, } \\
\text { - } \text { Tullowships } \\
\text { - Subsidion fee reimbursement meals, clothing, housing } \\
\text { - Subsidized transport }\end{array}$ \\
\hline
\end{tabular}




\begin{tabular}{|c|c|c|}
\hline & & $\begin{array}{l}\text { - Childcare subsidy } \\
\text { - Other direct and indirect financial } \\
\text { benefits }\end{array}$ \\
\hline 2 & $\begin{array}{l}\text { Non-Financial } \\
\text { Incentives }\end{array}$ & $\begin{array}{l}\text { - } \text { Holiday/vacation } \\
\text { - Safe and clear workplaces } \\
\text { - Job, stability, security/job autonomy } \\
\text { - } \text { Flexibility in working time and job } \\
\text { sharing } \\
\text { - Planned career beaks } \\
\text { - } \text { Occupational health/counseling service } \\
\text { - Direction, supervision } \\
\text { - Support for career advancement } \\
\text { - Access to or support for capacity } \\
\text { development such as training or } \\
\text { - } \text { education, etc. } \\
\text { - Soaching and mentoring structures } \\
\text { - Equal opportunities policy } \\
\text { - Others }\end{array}$ \\
\hline
\end{tabular}

Source: Buchan, Thompson \& O’May (2000)

\subsubsection{FINANCIAL INCENTIVES}

Financial incentives are developed separately according to different types of people and organizations. In the context of public and private organizations as well as in the literature of human resource management there is a long tradition of expressing the existence of financial incentives as remuneration (Lawler, 1971; Lathan, 2007).

Financial incentives are developed to satisfy basic human needs, encouraging and pushing people to do their best work performance, the recruitment of their capabilities and enhance their competencies level. Financial incentives are also designed as a means of payment to increase productivity and improve employee 
work performance. Therefore, the more employees produce the more they can get. Whereas, a decrease in quality or quantity of work might deprive employees from earning part or all of their incentive (Jadallah, 2007). Financial incentives are designed to give the employee some control over their income as the employee's income will be based on their performance, to create a greater sense of responsibility of the job on the part of the employee, and to stimulate the employee to work harder than what he/she usually does (Yavuz, 2004; Lawzi, 2005)

One feature of financial incentives is that it is variable in nature. For instance, financial incentives are often called variable pay, as there are not guaranteed (Gross, 1995). It also refers to pay that is contingent based on actual performance of employees, as different to an entitlement. Another study of financial incentives shows that some employees are motivated by rewards and that money is a strong motivator for them (De Cenzo et al, 1996). According to a study on compensation and incentives conducted by Baker, Jensen and Murphy (1988) one person might not be as responsive as others to the same reward. For instance, one person might appreciate a compliment or recognition from their organization while another would prefer financial benefit like a salary increase. This finding has also been supported by a survey that was conducted in a Malaysian organization that found that most of the employees prefer to have a cash reward (Rafikul I. \& Ahmad Zaki Hj. 2004).

In addition, financial incentives do not always deal with direct benefits like pay or wage, bonuses, pensions, allowances, etc. Sometimes it could be developed as indirect financial benefits such as subsidized food, accommodation, transportation, educational fees, childcare and so on (Buchan, Thompson \& O’May, 2000).

From the above discussion, it can be concluded that financial incentives can be designed and developed into different forms with regard to different people, organizations and situations. And their main purpose is to encourage and motivate people for greater achievement.

\subsubsection{NON-FINANCIAL INCENTIVES}

Although financial incentives are the key to improving employees' motivation, job satisfaction and better performance, there are a number of non-financial incentives that may represent more effective means of improving quality of work performance as well as motivational level (Franco, Bennett, Kanfer \& Stubblebine, 2004). A 
simple definition has been given by Mathauer and Imhofff (2006) non-financial incentives as any means of incentives that do not involve directly with money, transfers of monetary values or equivalents. Assaf (1999) and Bunchan, Thompson and O'May (2000) also state that non-financial incentives can be tangible or intangible and usually do not involve direct payment of cash. The authors also argued that in the organization, a non-financial incentive could be in the form of employee participation in decision-making, staff recognition such as issuing a certificate of thanks and appreciation, providing extra training courses as a part of capacity development programmes, or organizing parties for distinguished staff.

Some important aspects of non-financial incentives such as promotion, job recognition, meaningful job and opportunities for self-development, advancement are successfully developed in an attempt to improve the working environment, enhance performance and increase productivity (Lawzi, 1995). In addition, non-financial incentives can also promote staff loyalty, enhance more interaction and cooperation among subordinates and superiors, enable more opportunity for staff participation or involvement and so on.

Non-financial incentives are sometimes known as moral incentives, which is concerned various aspects of psychological needs, and the increase concentration of these aspects are come after the emergence of human related theories (Akaili, 1996). Moral incentives mostly based on the respect of a human being who has emotional feeling, hopes and aspiration. Meanwhile, a similar study on moral incentive has been conducted by Johnson $(2005, \mathrm{p} .1)$

"A person has a moral incentive to behave in a particular way when he has been taught to believe that it is the right or admirable thing to do. If he behaves as others expect him to, he may expect the approval or even the admiration of the other members of the collective and enjoy an enhanced sense of acceptance or self-esteem. If he behaves improperly, he may expect verbal expression of condemnation, scorn, ridicule or even ostracism from the collectivity. And he may experience unpleasant feelings of guilt, shame or self condemnation".

From the above reviewed, it can be concluded that non-financial incentives are a set of motives, which are intended to meet the emotional and psychological needs 
among the employees. Also, it is an internal consequent for the individual such as job enrichment, job participation, responsibility, promotion, vacation time and the nature of supervision. In brief, a non-financial incentive has significant potential to fulfill employees needs and motivate them without using or affecting financial resources. It plays an important role in increasing motivational levels as well as promoting employees' work performance.

\subsubsection{THE EFFECTS OF INCENTIVES IN THE ORGANIZATION}

Incentives are generally developed to generate employee motivation, satisfaction, and greater performance. The link between the three variables has been widely discussed and debated among the researchers, scholars and practitioners (Lawler, 1971; Latham, 2007). They argue that the effectiveness of incentives for reaching higher behavioral outcomes of employees is based on the degree to which those incentives are perceived to fulfill or satisfy their needs. For example, if the employee overwhelmingly desires job autonomy and perceives the amount of money or benefits are likely to satisfy this need, then the payment is likely to motivate them to perform the job. Since employees' satisfaction could be both the cause and outcome of overall performance, organizations should demonstrate the link between reward and performance in order to motivate employees (Latham, 2007). Latham also suggests that if there is no link between employee performance and satisfaction or there is a negative one, then the organization clearly has an ineffective system of incentives. In addition, with an effective incentive, employees could gain several social and psychological benefits as a result of improving their purchasing power to satisfy his/her needs of goods and services (Al-Jahni, 1998). Therefore, it can be concluded that incentives have great potential for improving employee work performance and increasing production efficiency through encouraging individuals or groups to act in a desired and productive way.

\subsubsection{THE POSITIVES EFFECTS OF INCENTIVES}

Incentives have many positive effects within the organization. First, they have been used as a guideline to show employees what the organization wants to achieve and what they value and prioritize as important toward their jobs. Second, incentives can be used as an effective tool to attract the desired, competent people into the organization, because people that value this form of attraction will be drawn to work 
there rather than people that are only seeking steady benefit. A third reason is the general belief that incentives can be used to motivate employees to work harder, to make an extra effort in order to achieve the organizational goal (Merchant \& Van der Stede, 2007). Even when individuals have acquired a strong capacity, skills and knowledge, these do not always transform into enhanced quality of work performance. According to Kamoche $(1997$, p2) "the problem lies not in the lack of skills, but the lack of strong incentives to use these skills optimally".

Even though some studies may argue that extrinsic and intrinsic motivation lead employees to different satisfaction. Extrinsic motivation is a kind of motivation, which is gained from an externally influenced environment, while the intrinsic motivation indicates that under certain circumstances those who work for an organization are prepared to undertake a task for immediate need satisfaction or for their own benefits, and those tasks will be performed without financial rewards or payments (Calder \& Staw, 1975; Deci \& Ryan, 1985). But this finding may contradict the general standard of economic consumption that employees are selfinterested.

\subsubsection{THE NEGATIVE EFFECTS OF INCENTIVES}

Despite all these arguments supporting the positive effects of incentives on employee motivation, there are some views regarding the possibility of failure or some negative effects concerning the implementation of employee incentives. According to Angaria (1999), some negative affects of employee incentives especially financial incentives still exist. According to his study, financial incentives could push the employees to work hard, often affecting the employees' physical or psychological condition in the long run and affecting their social and humanitarian issues such as the individual age and other circumstances. He also argues that, in some circumstances, incentives can be used as a control tool to manage the employees within the organization. It could be motivated when we use an agency context, based on agency theory the model of man as an individualistic person, a self-serving person, which implies that rewarding desired behaviour will lead the staff to act in a certain way, and in the best interest of the organization. In contrast, when incentives are used in the environment of stewardship, there is a risk of decreased motivation since the employees according to this theory will act in the best interest of the 
organization (Davis, Schoorman \& Donaldson, 1997; Harvey, 2005). They also express that the attempt to inspire and influence employee's behavior can be considered as counterproductive because the entire designed procedures undermine their natural actions. In light of these, it can be assumed that incentives with their advantages have great potential to motivate employees. However, there is no guarantee that they can always lead to efficiency and effectiveness in the organization. Furthermore, the existence of highly motivated employees in the workplace do not necessarily mean that they are the best performing ones.

\subsubsection{INCENTIVES IN PUBLIC ORGANIZATIONS}

Various studies on the effect of employee incentives on work performance and productivity have been a prominent point of interest particularly in human resource management in the private sector. However, research within the public sector has been largely ignored. This may be due to the fact that the goal of the public sector differs from those in the private sector (Benh, 1995; Reilly, 2003). Meanwhile, contemporary researchers in the public sector believe that while employees in private organizations are motivated to enhance their work qualities and increase productivity, public organizations should also seek and follow this strategy to upgrade their existing work performance and maximize social welfare of the people in general (Wright, 2000). In reviewing the public service motivation, incentives are described as a kind of motivation factor that induce public servants to perform meaningful public service. Work motivation in the public organization is an ethic that is oriented toward public service and with a sense of duty (Staats, 1988). According to research conducted by Morgan and Baser (2007) in the public sector, incentives are used not only as an essential tool in an attempt to build and enhance human capacities, but also serve as a core part of the ongoing process and much needed particularly in the period of civil service reform efforts that take place in many less developed countries.

\subsubsection{EVIDENCE ON THE IMPLEMENTATION OF INCENTIVES}

In this part, we will highlight a number of studies that provide some interesting evidence to illustrate the successful implementation as well as the significant effect of incentives on the output of an organization. The information below typically focuses around the two questions: (1) what were the effects of the incentives on the outcome 
of an organization? And (2) what types of incentives are most desired among the employees particularly in the public sector?

There is much less evidence concerning the public organizations than private firms. One fruitful study has been conducted by Kahn, Silva and Ziliak (2001) who examined the impact of introduced performance pay on the tax collection authority of Brazil. The idea involved payment of financial incentives based on individual and group work performance in detecting and fining tax evaders. The amounts involved are remarkable - bonuses were often worth more than twice of the mean annual salary. The authors had created a comparative indicator by using a panel of six years on selected regions, three years before the development of incentives scheme and three years after. The findings show that the scheme had a significant effect. As a result, the fine collections per inspection dramatically increased compared to the estimated factual data. This is not a difference between studies because the reform was introduced almost nationwide, but Kahn, Silva and Ziliak only investigated whether tax compliance responded to the social, political and economic changes. The pattern of changes in fines suggests that it is indeed attributable to the performance pay reforms. Also the performance pay reform under the incentives scheme has a significant positive impact on the entire work performance of employees.

Alonso and Lewis (2001) used multiple regressions on responses by 35,000 employees from the United States federal services. Those selected employees were tested to find out the correlation between public service motivation and work performance. The result of their studies have shown that there is mixed evidence on whether public service motivation was effected positively on the quality of work performance both grade and rate. And that some clear evidence is needed to prove that those who expected to receive either financial or non-financial rewards for their extraordinary performance attained higher grades and performance rating.

Another study has been conducted by Genebra (2003) on the comparison of employee motivation between the public and private sector in South Africa. The study found that nurses in the public service often mentioned being overburdened by work and indicating an intention to leave for better pay and working conditions. Similar studies have been carried out by Crewson (1997) and Jurkiewicz, et al., (1998) those studies have found that managerial employees in the public organization place less value on 
financial incentive and more value on other services compared to private organization. In concluding the report Genebra (2003) raised a pertinent question, can the human aspect of the public service provider be improved in South Africa without developing or restructuring the incentive system within the public bureaucracy? Therefore, it is obviously understood that this question is sought to identify and deepen understanding of the effectiveness of employee incentives in boosting work performance in public organizations.

Some studies examine what types of incentive are most desired among the employees particularly in the public sector. One particular study in the United States of America been conducted by Houston (2000) compared public and private organizations with regard to the incentives that they valued most in the workplace. Respondents were asked to rank the following job related characteristics: high income, short working hours and much free flexible time, job security and stability, opportunity for development and advancement, work that is important and provides more feeling of achievement. The result of this research study demonstrated that public employees are more likely to be motivated by the intrinsic reward of the work that is important and provides a feeling of achievement, while private employees are more likely to place a higher value on extrinsic reward motivators such as high income and short work hours. In addition to this, public employees seem to place more value on job security and job stability compared to private employees. The study seems to indicate that people entering the public sector value economic wealth to a lesser degree than those who are entrants to the private organizations.

\subsubsection{SUMMARY}

Regardless of financial or non-financial incentives, their main purpose is to positively influence the working behaviour of people. In the workplace, incentives are usually developed among those who should be recognized and rewarded and thus encourage them to work toward the common goal of an organization, which can increase profitability, effectiveness and efficiency. In other words, incentives are designed to encourage individuals or groups to exert more effort, work harder and perform better. Incentives are a management tool, which has been used by various organizations to, trigger a motivational reaction and a change in human behaviour (Assaf, 1999; Alwabel, 2005). Also, they have been playing a potential role in pushing forward individual or team's capacity and moving their abilities, motivating 
them to develop knowledge, skills and balance between the need of an individual or group and organizational requirements. Both Assaf and Alwable suggest that the use of incentives not only as a defense strategy applied by failing organizations, but various organizations also use them as a positive action in recognition of the strategic role of compensation in further developing corporate goals. The essential point is that many organizations are beginning to encounter compensation choices, as the flexibility to try a new form of management is a crucial need. In brief, all organizations whether private or public, incentives are a key motivational tool, which allow them to operate effectively and efficiently in their function. Also, employees who are well motivated to work creatively and energetically toward the accomplishment of organizational goals are one of the most important inputs to organizational success.

\subsection{GENERAL OVERVIEW OF WORK MOTIVATION}

Despite the fact that multinational or large-scale complex organizations have existed for decades, focus on the roles of motivation is a recent phenomenon. Before the industrial revolution, the major types of motivation were implemented under the form of fear, physical punishment, social, financial. However, as manufacturing processes became more complex and more competitive, large-scale businesses or organizations were locally and internally merged which gradually eliminated many old working and management systems including social and exchange relationship. Also, this traditional pattern of behavior between employees and employers was replaced by the more recent, practical and effective way of interaction between employees and their organizations. In the current global context, most organizations or businesses are trying to enhance work performance as well as quality of their products and services in both internal and external operations. The reasons for doing this can vary depending on the organizational goals. On the other hand, the competition between organizations and businesses makes it more difficult to achieve their goal (Bolman, 1997). Work motivation is a primary factor for progress within an organization and business (Pare, Tremblay \& Lalonder, 2001). According to Pare, Tremblay and Lalonder (2001), one of the most effective strategies for achieving organizational or business goals is work motivation. The way organizations motivate their employees can impact on how employees perceive their working environment and culture within their organization. Most employees who are motivated produce a 
higher quality of work performance as well as work effectiveness. A number of theories have been developed to assist managers with increasing the level of work motivation within an organization. It is generally believed that when employees believe they will obtain a desired outcome by involving a specified behaviour, they will be more likely motivated to involve in that behaviour (Hackman \& Lawler, 1971). The authors also suggest that a job that allows employees to develop a sense of personal responsibility for a meaningful portion of the work, provides an ultimate result at work which is intrinsically meaningful, and provides feedback about employees' performance will provide those employees with greater motivation to exert more effort and be more effective.

\subsubsection{WHAT IS MOTIVATION?}

Motivation has been defined as "the psychological process that gives behavior purpose and direction, a predisposition to behave in a purposive manner to achieve specific unmet needs, an unsatisfied need, and the will to achieve, respectively" (Lindner, 1998, p.9). "Motivation is the force within an individual that accounts for the level, direction, and persistence of effort expended at work" Young (2000, p.3). Young also argues that motivation can be defined in many ways, and it depends on a real situation and the background of the person in question. For example, if we ask someone on the street, we may get a response like "it's what drives us" or "it's what make us do the things we do". Similarly, Halepota (2005) define motivation as "active participation and commitment to achieve the prescribed result". The author further expresses that the conceptualization of motivation is abstract because different results are the outcome of different strategies and tactics at different times. Therefore, according to Halepota, there is no one-size-fits-all strategy that can produce desired result at all times.

Related to motivation in workplace context, Antomioni $(1999, \mathrm{p} .11)$ has defined motivation as "the amount of effort people are willing to put in their work places on the degree to which they feel their motivational need will be satisfied. On the other hand, individual become de-motivated if they feel something in the organization prevent them from attaining good outcome". A simple definition of motivation has been given by Mitchell $(1982$, p.4) as "the degree to which an individual wants and chooses to engage in a certain specific behaviour". Vroom (1964, p.6) defines 
motivation as "a psychological process that causes the arousal, direction, and persistence of voluntary actions that are goals directed". In this regard, individual characteristics should be considered and identified before initiating any ideas concerned with rewards or job recognition because different individuals have different needs and interests based on their specific circumstances such as family, values and beliefs, education, work experience, and the community where they are based. For example, some individuals may prefer to work with well-paid job or any job with extra benefits like commission or bonus at the end of the year; whereas, some value a job with flexibility, creativity, autonomy or opportunities for capacity development and so on.

Motivation can be intrinsic or extrinsic. Sometimes people act not because they are intrinsically motivated, but rather because external factors prompt them to take action (Rayan \& Deci 2000). This type of motivation is called extrinsic motivation and it concerns whenever an activity is done in order to attain an outcome that is separable from the activity itself. Given the elaboration so far, it is possible to support that work motivation is about internal and external forces that influence an individual's degree of willingness, desire or choice to deal with a particularl action or behaviour.

In the context of the public sector, public motivation is defined as an individual's predisposition to respond to motives grounded primarily or uniquely in the public institution or organization. The term "motives" is used here to refer to psychological deficiency or needs that an individual feels some compulsion for fulfillment (Perry \& Wise, 1990). Public motivation is a general altruistic motivation that serves the interests of a community of people, a state, a nation or mankind. It is also a study about public ethics or public service values, and the construct has been referred as a commitment to public interest, commitment to public good with a sense of duty, responsibility and contribution (Rainey, 1997; Simeone, 2004).

Even though motivation is defined in different ways under different contexts, the core concept is related to human behavior. It was started from human needs and those needs make individuals to behave in certain ways, which lead to goal orientation It can be concluded that motivation is an on going process of human behavior which starts with needs, then is oriented by goals and finally complete with the fulfillment of those needs. 


\subsubsection{VARIABLES AFFECTING THE MOTIVATION PROCESS}

According to a study conducted by Steer and Porter (1987), three variables affect the process of motivation. The first is individual characteristics. This category includes some sub-variables like individuals' interests, their attitudes and needs. The second variable is job characteristics, which contains some variables such as rewards, level of job autonomy, duty, responsibility and so on. The last variable concerns the characteristics of the work related environment. Some positive and negative impacts in the workplace are unavoidable. Those impacts are mostly caused by individual or groups within the organization, vertical and horizontal cooperation and communication, and work system such as rewards for higher achievement. Since the main purpose of incentive is to promote and increase employee motivation, some of these three variables should be taken into account. Table I below shows the three key variables which have a strong on motivational process.

Table I: VARIABLES AFFECTING THE MOTIVATION PROCESS

\begin{tabular}{|c|c|c|}
\hline 1 & Individual Characteristics & 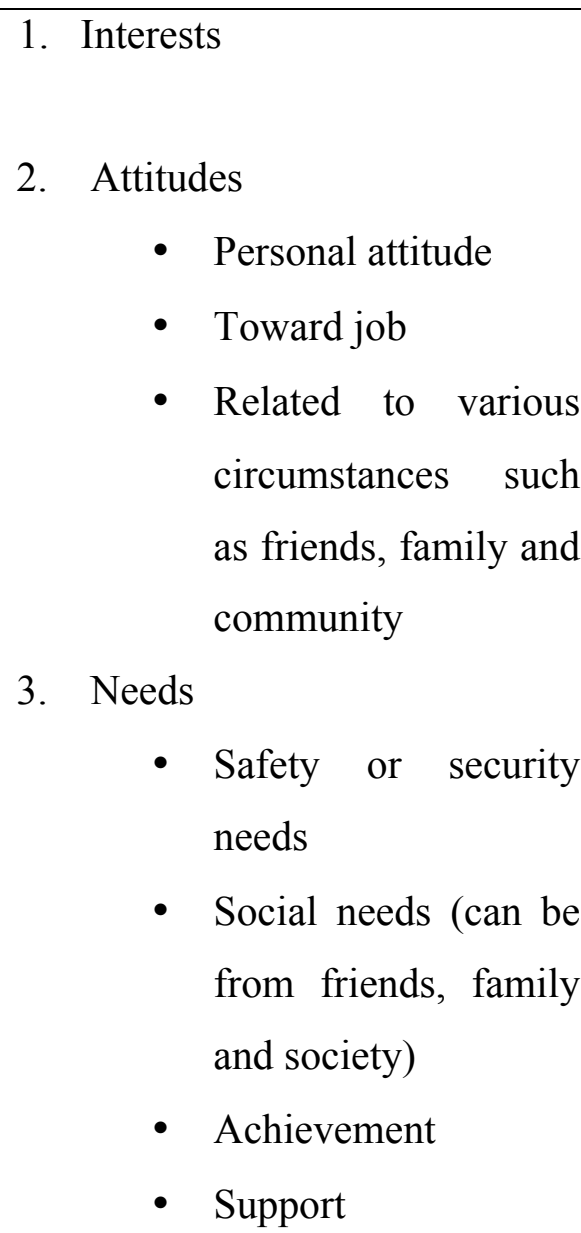 \\
\hline 2 & Characteristics of Job & 1. Rewards \\
\hline
\end{tabular}




\begin{tabular}{|c|c|c|}
\hline & & $\begin{array}{l}\text { - } \text { Salary increases } \\
\text { - Annual bonus } \\
\text { - Extra commissions } \\
\text { - Other financial benefits } \\
\text { 2. Degree of autonomy } \\
\text { 3. Amount of work, direct } \\
\text { 4. Responsibility, } \\
\text { 5. Pecountability } \\
\text { 6. Degree of variety in tasks }\end{array}$ \\
\hline 3 & Working Environment Characteristics & $\begin{array}{l}\text { 1. Immediate work environment } \\
\text { - From co-workers } \\
\text { - From supervisors } \\
\text { 2. Organizational actions } \\
\text { - Reward system } \\
\text { - Reward practices } \\
\text { - Individual rewards } \\
\text { - Group or team rewards } \\
\text { - Roles or policies in the } \\
\text { - Workplace } \\
\text { - Working system } \\
\text { Organizational culture }\end{array}$ \\
\hline
\end{tabular}

Source: Steer and Porter (1987, p.28)

The effectiveness of employee incentives depend on one or more of these variables. Steer and Porter (1987) express that people are motivated by unmet needs and interests, and these vary depending on their personal circumstances, educational background, past experience, family, friend, culture, beliefs and so on. For example, some individuals may prefer monetary incentives or other financial benefits, while others may value opportunities for self-development and advancement. Therefore, it is obvious that understanding the different characteristics of individuals can enhance the effectiveness of employee motivation. Wright (2000) also says that employees in one organization may differ from employees in another organization as a result of 
attraction, recruitment and even post-recruitment adaption and attrition processes. Thus, it is possible that individuals who work for public organizations are motivated by values that cannot be found in private organizations. Therefore, key functions of individual characteristics should be considered because incentive programmes are developed in line with the attitudes of individuals, their needs and interests (Steer \& Porter, 1987).

It is also important to focus on the characteristics of a job when considering incentives in the context of motivation. Research by Wright (2000) has conjectured that what a person does at work, the nature of the job or fulfilled tasks, can influence work motivation. Thus, it is important to focus on the characteristics of a job, because the nature of the job strongly affects the successfulness of incentive in the context of motivation. According to Table 1, job related characteristics could be in the form of reward, work autonomy, workloads, direction, variety and responsibility of tasks and so on. It is really essential to identify these factors at every level, since not every one has the same wants or needs at the time or the same level. According to Herzberg (2003) challenging, interesting and meaningful work enables employees to reach higher order needs such as self-esteem and self-actualization. Meanwhile, Hackman and Oldham (1980) suggest that jobs that are meaningful, interesting and challenging motivate greater effort and enhance employee satisfaction.

In addition, there are some studies on the negative aspects of job characteristics like workload pressure, time and resource constraints. There are the main factors effecting work motivation and job satisfaction (Vroom, 1964). If workload pressure, time and resource constraints are perceived as excessive, they can hinder the employee's effort to effectively and successfully perform tasks and this will lower work motivation. Therefore, when a job is perceived as excessively demanding while resources are not available the situation is not conducive to motivating an employee to contribute their work effort (Amabile, Conti, Coon, Lazenby \& Herron, 1996; Turnipseed \& Murkison, 2000). In this sense, it might be concluded that by understanding the influence of job characteristics may contribute to the effectiveness and efficiency of work motivation as well as the entire operation of an organization.

The last influencing factor on the motivation process is the working environment or work context. The environment in the workplace includes both people and 
organization. People here could be individual or peer group interaction. Superior management and leadership styles are also important in the context of motivation, because one of the main duties of a supervisor is structuring of work activities, developing abilities and skills for subordinates to perform their job and pursue their own goals. Furthermore, supervisors are able to provide job related feedback, suggestion and corrections as well as allowing employees to be involved in various activities including the decision-making process. The nature of interaction between subordinates and supervisors, the effectiveness of coordination and cooperation among them also affect the entire motivational process. Finally, various actions in the organization such as rewards, recognition, working procedures, systems, organizational culture are part of the workplace environment, and are also important for the success of the motivation process.

\subsubsection{THEORIES OF MOTIVATION}

Based on the above literature review, each person is motivated by different things thus it is important to know how they are motivated in an attempt to direct motivation towards the achievement of organizational goal setting. This section is going to elaborate the different theories of motivation which reflect the motivational processes. According to Samson and Daft (2000), several motivation theories focus on different variables to explain motivation within the organization. These theories give different perspectives which are usually not contradictory but complementary. Since it is impossible to cover all of those theories, this section will highlight content theories, process theories and reinforcement theories.

A content theory generally focuses on the study of human needs and does provide insight into the needs that motivate employees within the organization (Samson \& Daft, 2002). People have different needs and desires such as money, lifestyle, types of work, place of work, recognition of work, possession, achievement and so on. These needs convert into an internal drive that motivates specific behaviour in an attempt to satisfy the needs. Therefore, the needs of employees will reflect the effectiveness of current or future incentives system in the workplace. For example, if most employees in the workplace need salary increases or extra financial benefits more than job recognition or job autonomy, they would not be motivated or satisfied if the organization only provided non-financial incentives. 
Process theories usually deal with thought processes that have a strong effect on human behavior (Samon \& Daft, 2002). Samon and Daft (2002) state that people often assess their daily interaction with the surrounding working environments. In this regard, process theories of motivation consider what people are thinking about and when they decide whether or not to exert effort into a specific action. Furthermore, process theories concern how people select behaviours in order to match or meet their needs and determine whether their choices were successful, and how they seek rewards in the current environment of their workplace (Samson \& Daft, 2002).

Reinforcement theories refer to anything that causes a certain behaviour to be repeated or inhibited. The four reinforcement tools are positive reinforcement, avoidance learning, punishment and extinction (Samson \& Daft, 2002). In each of these cases, applying a pleasant or unpleasant event following a person's behaviour causes reinforcement. Positive reinforcement rewards people with a pleasant consequence following desired behaviours. According to Samson and Daft (2002), a good example of positive reinforcement is immediate recognition of an employee for arriving on time or doing extra work. Offering the employee a pleasant output for his or her behaviour will increase the likelihood of that behaviour occurring again. This pleasant output can be a monetary or non-monetary incentive. Meanwhile, avoidance learning, sometimes called negative reinforcement, is the elimination of an unpleasant outcome following desired behaviour. In the workplace, employees sometimes learn to behave in the desired manner as they attempt to avoid unpleasant situations. For instance, a manager stops warning or criticizing an employee because he/she sees that the employee does not show the incorrect behaviour anymore. With regard to punishment, Samson and Daft (2002) state that punishment is the opposite of avoidance learning. It typically occurs following the undesirable behaviour. For example, a manager may give an employee a lower grade during performance evaluation or appraisal, for performing a task incorrectly. The manager might expect that the negative outcome will serve as a punishment and may reduce the possibility of bad behaviour recurring. However, punishment is often criticized for being an improper way to indicate the correct behaviour. One last reinforcement tool, extinction, is the taking out of a positive reward. Extinction leads to a decline in the reinforcement of the undesired behaviour. If an employee does not receive job 
recognition such as pay increase or praise, he/she may begin to understand that their behaviour is not producing desired outcomes or is undesirable for the workplace. Therefore, the behaviour will gradually disappear if it is not continually reinforced (Samson \& Daft, 2002).

In brief, reinforcement theories are a different approach from content and process theories. Content theories and process theories simply look at the relationship between behaviour and its consequences, while reinforcement theories deal with the process when employees learn the desired work behavior (Samson \& Daft, 2002). The reinforcement approach to employee motivation ignores some issues related to the employees needs and thinking processes stated in the content theories and process theories. In addition to this, reinforcement theories seldom look at the connection between people's behaviour and their consequences. In contrast, the theories particularly focus on how to modify or change people's behaviour in their workplace or in the specific environment where they are located through the use of instant rewards, punishments or other mechanisms. According to Skinner (1956) a superior should motivate an employee by discouraging some undesired behaviours and encouraging desired behaviour exhibited by the employees. This might be accomplished by using a series of reinforcement tools such as offering a higher benefit or introducing capacity development programmes including on the job training, which are granted when desired behaviour occurs.

\subsubsection{MASLOW'S HIERARCHY OF NEEDS THEORY}

One of the most prominent theories that identify and describe human behaviour toward their needs is the theory of hierarchy needs by Abraham Maslow. According to Maslow (1943), people are motivated to satisfy their needs and those needs could be classified into five categories ranking from the lowest to the highest. The first three needs (physiological need, safety needs and social needs) are categorized as lower level needs while the last two (esteem needs and self-actualization needs) are characterized into higher level needs. Abraham Maslow also argued that each level of need must be fully satisfied before they reach the next higher level need. 


\section{Diagram of Maslow's Hierarchy Needs}

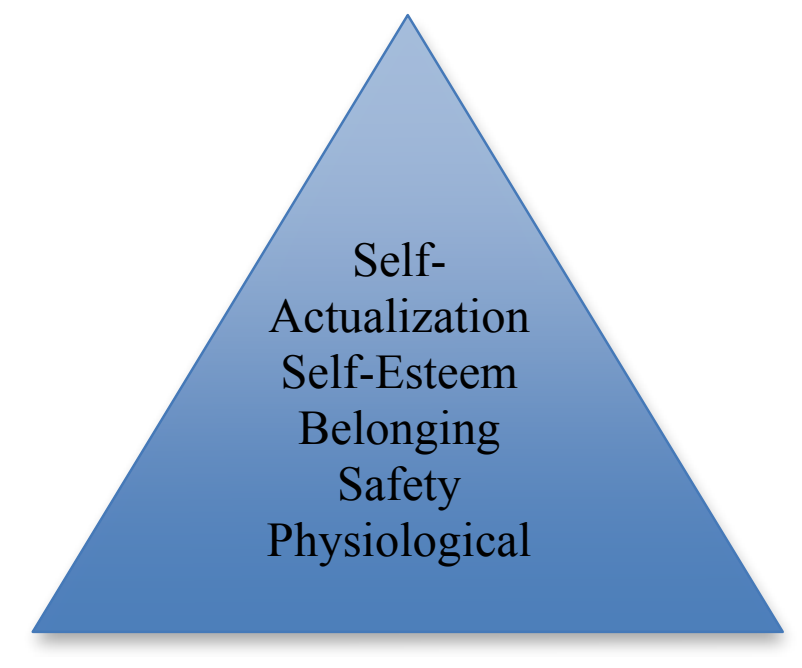

Lathan \& Ernst (2006)

- Physiological needs: the primary need at the bottom of the triangle. Physiological needs are generally known as the most basic needs of human beings for supporting and sustaining their lives, for instance: food, air, water, medicine, sleep and education (Latham \& Ernst, 2006). Based on the Physiological needs, organizations or businesses must provide and support their workers with sufficient benefits that enable them to afford living conditions. The point is that without adequate support especially financial support people will not be able to devote much time and effort to his/her organization.

- Safety needs: These needs occur when the physiological needs are met. These needs are required for protection from or against any physical and emotional threat and harm, to be freed from any dangerous situations, free of the fear of losing a property, a job, food and shelter. The main purpose of these needs is to have a safe place, secure income, medical insurance, sufficient paid, and other benefits (Latham \& Ernst, 2006). In short, organizations can ensure a safety- 
working environment by providing some safety mechanisms such as health insurance, safety guideline and work instructions.

- Belonging or social needs: These needs are activated after the safety needs are fulfilled. People need to belong, to be accepted and loved by other people because they are living in society. They like to have friends, family and communities. Also, they try to satisfy their needs for relationship, friendship, affection and acceptance. Moreover, cooperation and interaction between people and people in the society are needed since they are social beings. In an attempt to meet these needs, businesses or organizations have to encourage their employees to participate, to be a part in the various social activities such as party, group discussion, team building activities and so on (Latham \& Ernst, 2006).

- Esteem needs: These needs occupy the third level of needs and emerge after social needs are met. These types of needs are to be held in esteem by the person itself as well as by others. Also these needs initiate great satisfaction as self-confidence, prestige status and power. They usually combine both external esteem factors like states, attention and safe recognition and internal factors such as self-respect, self-achievement and autonomy (Latham \& Ernst, 2006). In order to fulfill these needs, organizations can initiate any rules or activities that fit their internal culture such as employees of the month, letter of recognition or best achievement party and so on.

- Self-actualization: Among other needs in Maslow's hierarchy, selfactualization occupies the highest need which can develop, fulfill and maximize one's potential, self-fulfillment and accomplishment. Those who reach this level try to maximize their outcome, skills and knowledge in order to achieve their desired goal and also can be a valuable asset to the human resources of an organization (Latham \& Ernst, 2006). 
The above needs theory has been supported by Mager and Sibilia (2010). The authors suggest that in order to achieve long-term sustainability, motivation should be implemented based on Maslow's hierarchy need. If people's basic needs are lacking, personal safety, belonging, self-esteem and self-actualization cannot develop. This could result in lack of interest to develop and progress in both short and long-term goals (Latham \& Ernst, 2006). Therefore, in order to motivate people effectively and productively, organizations or businesses need to know where people are placed on the hierarchical pyramid and then to focus on meeting people's needs at that level (Mager \& Sibilia, 2010). From this point of view, various organizational programmes including corporate sustainability programmes, remuneration, benefits, job satisfaction and a better working environment must be in place and guaranteed before identification with sustainability values can be expected (Latham \& Ernst, 2006; Mager \& Sibilia, 2010).

From the above discussion, Maslow's hierarchical needs are crucial for recognizing the needs of people. At the same time, it is important for both businesses and organizations in the context of rewards and recognition, where financial and nonfinancial incentives are generally used and have become the most potential factor to satisfy and motivate people to work harder, to improve their performance and finally to successfully achieve their goals.

\subsubsection{ERG THEORY}

Maslow's hierarchical needs (physiological, safety, social, esteem and selfactualization) correspond with the three primary needs in the Alderfer ERG theory which suggested that each of these needs are necessary for existence, relatedness and growth (Greenberg \& Baron, 2003). According to Alder's theory, existence needs generally respond to physiological needs and safety needs of Maslow's theory, while the relatedness needs respond to Maslow's social needs and growth needs respond to esteem and self-actualization needs. However, the key difference is that the three human needs of Alder's theory (existence, relatedness and growth) can be motivated at the same time and might not be activated in any hierarchy order. This means that a person's need may take precedence over others regardless of whether the other needs have been fulfilled or not. This can be implied to some staffs in an organization who 
prefer to have financial incentives such as bonuses or salary increases, whereas, some prefer non-financial incentives such as a good working environment, flexible working hours, work autonomy, good working conditions, training programmes rather than having monetary incentive in the first instance. In contrast, Maslow's pyramid needs need to be in order from the lowest to the highest. This means that human basic needs must be fulfilled at the first level before reaching other needs. This also implies that financial incentives are essential to cope with living costs and condition. In short, Alderfer ERG theory and Maslow's theory are quite similar, just the way Alder's approach activates is more much flexible and simpler than Maslow's approach.

In addition, Alderfer's ERG theory has pointed out the need for businesses and organizations to find ways to fulfill the needs of not only employees' lower level needs (basic needs) but also higher level needs (social needs) by developing some group activities or social events like encouraging employees to participate in decision-making, recognizing higher performance of employees, offering more opportunities for development and growth (Samsone \& Harackiewicz, 2000).

\subsubsection{MC CLELLAND'S THREE NEEDS THEORY}

McClelland (1961) proposes that an individual's specific needs are acquired over time and generally shaped by one's early life experiences. He stated that intrinsic motivators are important to meet personal needs, because they describe a pattern of how an individual may behave. In addition to this, individual needs are categorized into three different needs - needs for achievement, needs for affiliation and needs for power. A person's motivation and success in particular job functions are affected by these three needs.

- Achievement: Those with a high need for achievement seek to excel and they tend to avoid both high and low risk environments. Predominantly, the needs for achievement often motivated people to avoid low risk environments because the easily attained success is not seen as a genuine achievement. Meanwhile, in high risk environments, the need for achievement motivated people to see the outcome as one of chance rather than the results of one's own efforts. High-risk achievement individuals prefer work that has a moderate probability of success, ideally a $50 \%$ chance. These kind of needs encouraged individuals to get regular 
feedback in order to monitor the progress of their achievement. Usually they prefer either to work alone or work with others similar to them (McClelland, 1961). Similarly, Atkinson and Feather (1966) studied motivational factors for achievement, they determine an individual achievement orientation toward separate motives in order to achieve success, and to avoid failure.

- Affiliation: Those with a high need for affiliation need harmonious connections with other people and need to be recognized and feel accepted by other people. They usually tend to conform to the norms of their work group. High affiliation need people prefer work that provides significant personal interrelationship. They perform well with others especially in customer service or client interaction environments (McCleland's, 1961).

- Power: An individual's need for power can be one of two types - personal power and institutional power. Those who need personal power want to direct or lead others, and this need often is perceived as undesirable. Persons who need institutional power (also known as social power) want to organize the efforts of others to further the organizational goals (McCleland's, 1961).

\subsubsection{Motivation-Hygiene Theory}

Frederick Herzberg studied the factors in the workplace that cause satisfaction and dissatisfaction among employees. He found that the factors causing job satisfaction are different from those causing job dissatisfaction and both factors do not contradict or oppose but complement each other (Herzberg, 1966). According to his study, two distinct factors largely contributed to an employee's work behaviour. The first motivating factors or motivators, which could lead to job satisfaction, are associated with the nature of the work itself. They are job-related practices such as:

- Achievement

- Recognition

- Responsibility

- Opportunities for promotion

- Job autonomy 
- Opportunities for development, growth and advancement in the job.

Herzberg also argued that when motivators are absent, employees are neutral toward work; in contrast, when motivators exist, employees are highly motivated to excel at their work.

The second factor is hygiene factors or dissatisfaction, which includes the following:

- Pay and benefits

- Organizational policy, administration and other procedures

- Relationship with management and co-workers

- Physical work environment

- Direction and supervision

- Status

- Job stability or job security.

Based on Herzberg's theory, hygiene factors refer to the absence or presence of job dissatisfaction. When hygiene factors decrease, it could lead to job dissatisfaction. These factors have been considered as maintenance factors that are necessary to avoid dissatisfaction but they do not themselves contribute to job satisfaction. In-line with Herzberg's view, unsafe working situations or a poor working environment will cause workers to be dissatisfied with their job, but the removal of those negative factors will not lead to a high level of job satisfaction.

However, some studies have found some contradictions to Herzberg's motivation theory (Bowditch, James, Buono \& Anthony, 1997; Dubrin \& Andrew, 2002). Based on Herzberg's theory, hygiene factors are related to dissatisfaction rather than satisfaction. Another contradiction with Herzberg's theory is that some employees show no particular interest in such motivators as an opportunity for development and advancement (Dubrin \& Andrew, 2002). He also states that Herzberg's theory implication in real work life for supervisors or managers in the organization who want to motivate their employees might provide their employees with flexible policies, be connected with their own employees, recognize the good work from their employees and give some opportunities for development and advancement. Based on Herzberg's theory, adequate hygiene factors should be provided to meet the basic 
needs of employees and to prevent dissatisfaction with the job. Furthermore, motivators that have a strong effect on the work should be integrated to the process to meet higher level needs and lead employees toward higher achievement and greater job satisfaction.

\subsubsection{JOB CHARACTERISTIC THEORIES}

Job characteristic theories have been used by various businesses and organizations in an attempt to explain what kinds of characteristics a motivating job has (Hackman \& Oldham, 1980). Hackman and Oldham argue that jobs can be redesigned through various enrichment processes to positively contribute to the motivating potential of a job. The theory identifies five main job characteristics: variety of skill, task identity, task significance, job autonomy and feedback. A task, as a part of task identity, can be more enriching if employees can have the entire picture of the job through to its final stage rather than only dealing with a small part of the whole process. Moreover, the significance of the tasks in terms of its effects on other people can enrich the jobs. The importance of autonomy of the job is that when employees have the chance to control their work schedule and the process, job enrichment can be developed. Lastly, feedback is also important in terms of job enrichment because it generally provides employees the opportunities to enhance their work performance, give some space for adjustments in an effective and timely manner, particularly if they know where they are going (Hackman \& Oldham, 1980). According to Hackman and Oldham (1980) all these job characteristics can be used to enrich the jobs, and the job will be more enriching when employees utilize their multiple skills and talents instead of reusing or repeating one skill over and over again.

\subsubsection{INTRINSIC AND EXTRINSIC MOTIVATION}

Motivation has been developed into two different categories "extrinsic motivation" and "intrinsic motivation" (Deci \& Rayan, 1985; Sansone \& Harackiewicz, 2000). Extrinsic motivation exists when human behaviour is performed to attain externally administered incentives. In addition to this, extrinsic motivation is related to "tangible incentives" such as pay, wages, bonuses, cash, materials, possessions, and other forms of direct and indirect financial benefits. Through the identification of change of environmental contingencies, including extrinsic reinforcements, motivation increase has been observed in individual work behaviour including daily 
work attendance, punctuality, selling, cost reduction, productivity and work quality (Komaki, 1982). An example of extrinsic motivations is an employee being motivated to work hard, to work on time everyday with the desire to get more monetary reward or benefit award for perfect on time attendance.

Intrinsic motivation is a kind of self-generated urge which comes from inside a person and can influence individuals to behave or react in a particular way to lead them in a particular direction (Deci \& Ryan, 1985; Kasser \& Rayan, 1996; Decci, Koestner \& Ryan, 1999). The authors believed that intrinsic motivation exists when behaviour is performed for its own benefits rather than to obtain materials or any social reinforcement. Intrinsic motivation is likely to have a deeper and long-term effect because it is inherent in individuals. Intrinsic motivation may be the positive effects of employees' satisfaction toward their job and workplace (Rayan \& Deci, 2000).

Herzberg (1966) described that most tasks are intrinsically motivated when they are characterized by key a "motivator" such as job responsibility, desire for higher performance or great achievement, challenges, varieties, opportunities for development and advancement. Based on Herzberg's theory, intrinsic job factors are motivation, whereas extrinsic factors only placate employees (Herzberg, 1966). Herzberg also argued that workers get motivated when they are responsible for their work. He proposed that managers can give their worker more authority to their job and offer them individual and direct feedback in order to motivate and help an employee to connect to their work. According to Herzberg, intrinsic motivations have a strong connection toward incentives and work related incentives such as recognition of a higher performance, development and advancement opportunities or opportunities for individuals to use their abilities, knowledge and skills to investigate a job or solve any difficulty or problem which often arises in the workplace and so on. For instance, an employee may be willing to put in extra time and effort in an attempt to overcome various challenges and a desire to see the expected output. In this circumstance, the individual invests extra time and effort because the likely result of that action directly appeals to what he/she values.

In the context of human behaviour, and in an attempt to better understand extrinsic and intrinsic motivation, Edwards, Caplan and Harrision (1999) have introduced the 
implication of fit and misfit between the person (P) and the work environment (E), which is called P:E fit theory. P:E fit theory is one kind of theory that has been proven useful to more deeply understand job satisfaction and job stress. It also offers a wide range of predictions on how personal and environmental factors link and interact with each other in the ways that go beyond the simple linear relationship that characterizes most of the literature on intrinsic and extrinsic motivation (Edwards, Caplan \& Harrision, 1999). The authors elaborate that fit and misfit happen with respect to the amount of value that individuals place on intrinsic and extrinsic rewards, compared to the amount they receive in the job. In addition, a high degree of fit may produce positive outcomes, while misfit is usually considered as dissatisfaction, strain, stress, and a less positive outcome.

For broader discussion, Personal $(\mathrm{P})$ variables are the individual differences in the value individuals place on those rewards, whereas, environmental (E) both intrinsic and extrinsic reward are included in the form of the job characteristic (Edwards, Caplan \& Harrision, 1999). Both extrinsic and intrinsic rewards may seem to positively value all individuals. But the different level of needs and desires of individuals toward extrinsic and intrinsic reward is recognized and well understood (Kasser, 2000). Therefore, in order to better understand intrinsic and extrinsic motivation, the person and environmental fit theory ( $\mathrm{P}: \mathrm{E}$ fit theory) must be properly considered.

Based on the above reviewed literature, it can be concluded that there are several theories of motivation that focus on different variables in an attempt to provide more supportive information as well as to explain motivation in the organizational setting. In addition to this, some theories of motivation more or less relate to our study. Therefore, we are going to abstract the key concepts of each theory in conjunction with other aspects of the literature in an attempt to support our research findings and discussions. The following section will focus on some key concepts extracted from the theories reviewed.

\subsubsection{THE EFFECT OF MOTIVATION ON JOB SATISFACTION}

Research seeking to find better ways of motivating people in the workplace has caused some researchers and scholars to further concentrate on the psychological factors that can stimulate job satisfaction among employees (Smith, Kendall \& Hulin, 1969; Lock, 1976; Rainey, 1997). According to Herzberg (1966), the most 
potential motivators are the things that employees overwhelmingly desire and value. Motivation that leads to job satisfaction is associated with the nature of the work itself. Herzberg has included job related practices, such as job recognition, praise of employee's achievement, assignment of challenging jobs, accountability and responsibility as well as various opportunities for advancement and growth in the job, as important to motivation. He also argued that when motivators are present, employees are highly motivated to excel at their work with higher satisfaction. In contrast, when motivators are decreased or absent, workers are usually neutral toward work. Based on Herzberg's idea, monetary incentives may have the power to drive those employees to exert much time and effort in their work. Research also shows that for most people in most situations motivational tools such as pay, benefits or other promotions are important. However, the forms of motivations vary with the types of organization, the type of work and event with the particular job, and any form of motivation will not have the same appeal for every employee who dealt with the same job in the same workplace. If the organizations or businesses regularly and effectively observe or survey to identify these issues and appropriately consider their consequences, both organizations and employees would gain a great achievement. It is possible that organizations or businesses would increase their productivities, or gain competitive advantage through qualified, productive and motivated employees, while the employees would gain promotions, work related rewards as well as a satisfactory environment. Therefore, regardless of financial, physical or emotional circumstances, outcomes are still the main motivator of job performance. Thus when those things are tied up to performance, their attainment appears to be dependent on good performance (Lawler, 1971 \& 1966).

In the particular context of public service, job satisfaction is considered a result of public service motivation, as the specific work related circumstance seems to satisfy the individual's needs (Rainey, 1997). Rainey also found the higher willingness of public service for individuals, the higher level of satisfaction on the job. Naff and Crum (1999) support that public service motivation has a significant positive effect on job satisfaction and work performance and a weaker plan or intention to quit the job in the public organization. However, there is a significant contradiction toward the possible linkage between employee motivation and job satisfaction. Wright and Pandey (2008) argue that the relationship between employees' motivation in public 
service and job satisfaction is mediated by factors external to employee organization value congruence. This means the employees perceive that their values are congruent with those of the public sector organization they work for. Bright (2008) agrees that public service motivation has no significant relationship to job satisfaction and turnover intention among the public organization when personorganization fit is taken into account.

\subsection{JOB SATISFACTION}

\subsubsection{INTRODUCTION}

Job satisfaction can be one of the most essential tools for both businesses and organizations to indicate as well as monitor the feeling of employees toward their job and workplace. In addition to this, job satisfaction sometimes serves as predictor of work related behaviour such as employee participation, contribution, absenteeism or turnover. Job satisfaction is frequently considered to be the most intensively researched variable among organizational studies (Rainey, 1997). In addition, research has found that job satisfaction could lead to intention to quit or stay in an organization. Researchers have focused more on job satisfaction by conducting empirical studies and reviewing articles concerning job satisfaction (Locke, 1976). One common research finding is that job satisfaction is correlated with life satisfaction. This correlation is reciprocal, meaning people who are satisfied with their job tend to be satisfied with life and people who are satisfied with life tend to be satisfied with their job (Locke, 1976). In addition to this, an important aspect for organizations to note is that job satisfaction has a rather tenuous correlation to productivity on the job (Locke, 1976). Su and Bozeman (2009) conducted a study of job satisfaction in the public service working environment and found that the correlation between job satisfaction and organizational performance, behaviour and culture exists. Apart from the design of the job and individual's characteristics, a number of factors such as promotion, pay, direction, supervision, job stability, responsibility, group work as well as work related characteristics, are held to determine job satisfaction (Rainey, 1997). To sum up, job satisfaction can be an important indicator of how employees feel about their job and a predictor of work related behaviours as well as a vital piece of information to researchers, organizations and businesses. 


\subsubsection{WHAT IS JOB SATISFACTION?}

Job satisfaction is a kind of measurement to which employees have a positive emotional state, feeling or feedback towards their job within the organization, whereas, dissatisfied employees will somehow have a negative feeling and orientation towards the organization (Vroom, 1964; Lawler, 1973; Locke, 1976). Various authors have defined job satisfaction broadly. Among those, the most simplified definition was given by Smith, Kendall and Hulin (1969) when they defined job satisfaction as the feelings an individual or group of people has toward their job. Meanwhile five dimensions of job satisfaction have been identified: supervision, promotion, pay, work and co-workers. From this perspective, job satisfaction is a kind of creation of a number of essential dimensions and the different dimensions are part of a general concept of job satisfaction (Smith, Kendall \& Hulin, 1969). Apart from the design of the job and the personal characteristic, Rainey (1997) considers some key elements such as pay, promotion, job recognition, job security, superior supervision, employee participation and organizational structures as key criteria to determine job satisfaction.

Smith, Kendall and Hulin (1969) also expressed that job satisfaction is a process of the perceived characteristic of job in association with individual's frame of reference. In this regard, some specific job circumstances can be a satisfier, a dis-satisfier or irrelevant based on the comparable level of job conditions, conditions of other people inline with individual knowledge, capacity and past experience as well as various situational variables of the job in the present time. Therefore, job satisfaction is not an absolute phenomenon but is relative to the alternatives available to the individual.

\subsubsection{DETERMINANTS OF JOB SATISFACTION}

The primary determinant of job satisfaction is job intrinsic, which is commonly called motivation this includes job responsibility, opportunity for advancement, job recognition and so on. For instance, individuals or teams work hard because they like the job, and they are also motivated with the challenging work or project within the organization, and the opportunities for personal development and growth from the their current work. One survey conducted by Pawlowski, Suzanne, Datta, Patrin, Houston and Andrea (2005) on IT professionals working in state agencies and the University of Louisiana has shown that employees were often satisfied by intrinsic 
factors especially the constant learning and mastering of skills and knowledge related to new technologies, the intellectual challenge and creativity required for solving the complex working problems, and a sense of contribution and pride for their achievement.

The primary determinant of job satisfaction could also be an extrinsic factor. This is often referred to as hygiene factors such as organizational structure, policy and administration, salary, interpersonal relation with superior and subordinate staff, work conditions and so on. Also, an individual's level of satisfaction with his/her job can reflect the degree to which he/she values their job either implicitly or explicitly as it allows or fulfills the fulfillment of their job values (Locke, 1969, Pitts et al., 1995). Pawlowski, Suzanne, Datta, Patrin, Houston and Andrea (2005) conclude that employees are also satisfied with extrinsic factors such as benefit, job securities, flexibility of working hour, working environment including co-workers and their professional working condition.

\subsubsection{THEORIES OF JOB SATISFACTION}

\subsubsection{DUAL FACTOR THEORY}

According to Herzberg, Mauser and Snyderman (1959) job satisfaction consisted of two distinctive dimensions: job satisfaction and job dissatisfaction. These two dimensions are not at opposite ends of the same continuum, but instead represent two distinct continua. Kumari and Pandey (2001) examined the impact of job satisfaction and dissatisfaction on physicians' intention to change jobs the from public to private sector in Finland. The physicians worked primarily in a public hospital or public healthcare centre but also ran a private practice. The result showed that private practice had a positive, statistically significant effect on the intention to switch jobs. The findings also suggest job satisfaction decreased a physician's intention to switch sectors (from public sector to private sector); meanwhile, job dissatisfaction significantly increased the physicians' intention to leave the public sector.

Herzberg, Mauser and Snyderman (1959) also conclude that those job characteristics, which are essential and can lead to job satisfaction but not to job dissatisfaction, are considered satisfiers. According to the theory, the satisfiers are related to the nature of the work itself and the rewards that flow directly from the performance of that 
work. The most potent of these are those characteristics that foster the individual's needs for self-actualization and self-realization in their job. These characteristics also relate to intrinsic factors such as job autonomy, job recognition, high achievement, and opportunity for development as well as advancement. A sense of performing interesting and important work, job responsibility and advancement are the most important factors for a lasting attitude change. Achievement and recognition are also frequently associated with long-range factors of responsibility and the nature of the work itself. Recognition that produces good feelings about a job does not necessarily have to come from managers or supervisors; it might come from co-workers, subordinates or stakeholders (Herzberg, Mauser \& Snyderman,1959).

Another study on the effect of job characteristic on job satisfaction has been addressed by Hackman and Oldham (1976). The study has shown that job characteristics were widely used as a framework to study how particular characteristics of job impact on job outcomes and job satisfaction. The authors also state that there are five main job characteristics: skill variety, task identity, task significance, autonomy and feedback. These five main characteristics have a great influencing power toward job outcomes including job satisfaction and absenteeism.

\subsubsection{EQUITY THEORY}

Adams (1963) states that in order to satisfy employees, it is essential to ensure that equity exists among the employees in the workplace. Some key aspects like education, skills, experiences, job qualification are significant inputs to the job by every employee. The outcomes the employees receive from their jobs are pay, reward, benefits and other intrinsic rewards. Thus, whether a person's perceived input and outcome are balanced could determine satisfaction. The author suggests that when people perceive their input-outcome balance is favorable, and then equity exists and satisfaction will be the end result. In contrast, if the perception is that the input-outcome is unfavorable and inequity exists, then the end result would be that of dissatisfaction. Moreover, under the equity theory, either under-reward or overreward both can lead to dissatisfaction, although the feeling of the employees would be somewhat different. The theory suggests that under-reward leads to feelings of unfair treatment, whereas over-reward leads to feelings of guilt. 
Another important factor mentioned in the equity theory is that employees evaluate the fairness of their own input-outcome balance, by comparing it to the perceived input-outcome balance of the next person. If they recognize that their compensation is equal to what others receive for similar input, they will believe that the treatment from their workplace is equitable and fair (Adams, 1963). For example, when an employee perceives that he/she is required to work extra hours, to put more effort into work than others and receives the same benefits and rewards compared with other employees, the hard working employee will attempt to even out the perceived imbalance by working less hard.

The equity theory can particularly be observed in public organizations where public employees of the same knowledge, skills, experiences and status will get the same amount of wage, no matter how hard they work, how much time and effort they spend, and how effective they are in developing desired outcomes. In this regard, in order to avoid any negative feeling including dissatisfaction among employees, managers should ensure that where several employees are doing the same job with the same requisite level of effort to achieve the desired results, the prospective outcome, rewards and recognitions should be provided equally and fairly. Furthermore, managers should take action immediately to rectify any unfairness, imbalance and ensure that all employees do their fair share of work Otherwise, businesses or organizations may face less motivation, poor performance and dissatisfaction among employees.

\subsubsection{FULFILLMENT THEORY}

Research conducted by Locke (1969) shows that people's satisfaction is a function both of how much they receive and how much they feel they are supposed to receive and/or want to receive. Based on Locke's theory, people reacting to what they receive is not simply a function of how much they receive; their reactions are strongly influenced by different factors of what they want and what they feel they should receive. We know that some job related factors are more important than other job factors for each individual. It is thus important to consider and weigh those factors for the purpose of determining overall satisfaction of an individual. According to Vroom's theory, satisfaction is equated with valence (attractive) and added. He also sees job satisfaction in terms of the degree to which a job provides 
the person with positively valued outcomes (Vroom, 1964). For example, if we describe a person satisfied with an object, we mean that the object has a positive valence for him or her. However, satisfaction has a much more restricted usage. Usually we refer to a person's satisfaction only with reference to objects, which he/she possesses.

\subsection{THE LINKAGE BETWEEN INCENTIVES, JOB SATSFACTION AND WORK PERFORMANCE}

\subsubsection{CAUSAL RELATIONSHIP AND OUTCOME}

The link between incentives (rewards and/or recognition), job satisfaction and work performance are implied by focusing on the human factor in an organization, characteristics of a job and the work environment within an organization. In the public sector, public organizations are made up of people, and people here could be individuals, employees, and work teams. The different outcome of each component is in how much they involve and contribute to the organization. It is not only what they do but also how well they do it. The effective organizations make effective use of people knowledge and skills, which generally occur when people align their proper goals with that of the organization they work for. Meanwhile, job related characteristics and overall working environment are also important in the context of job satisfaction. In addition to this, the degree of self satisfaction felt by individuals or groups of people in the workplace can determine their overall performance, which means satisfaction positively affects work performance (Judge, Thoresen, Bono \& Patton, 2001; Kim, 2005). This proposition has theoretical roots, but it also reflects the general belief among scholars that "a happy worker is a productive worker". Therefore, when the problem of performance exists, it is far more advantageous to deal with or to increase workers' satisfaction than to deal directly with their performance (Vroom, 1964).

From this viewpoint, the overall work performance of an organization is greatly dependent on the productivity of individuals or groups within the organization. Therefore, to attract, motivate and retain good performance and highly productive staff and to be fair to all employees, an organization needs to set up and develop incentive schemes in order to reward and recognize employees' performance on the basis of their relative productivity (Martocchio, 2006). Similarly, Thorpe and Homan 
(2000) have emphasized the importance of employee motivation by mentioning the direct link between pay and productivity. In addition, Dubrin (2004) states that employee motivation through incentive largely focuses on linking pay to performance and this generally motivates people to work harder, better and those positive results are regularly monitored by managers particularly on overall productivity, responsibility and employee development. In return, team members should trust their manager, feel the job they are doing is meaningful and interesting. They also get rewards and/or recognition based on their efforts and contributions for the organization they work for.

Many studies have been carried out on the correlation or direct link between job satisfaction and employees' work performance (for example, Naff, Katherine \& Crum, 1999; Bright, 2008; Steijn, 2008; Judge et al. 2001; Kim, 2005), and the findings of those studies became strong support for the positive effects between job satisfaction and individual work performance. Among those studies, some have particularly concentrated on a cause, which is relevant for the provision of the public service, namely public service motivation. These studies on public service motivation have shown the existing correlation between public employee motivation and job satisfaction, and job satisfaction as a primary mediator between public service motivation and individual work performance (Naff, Katherine \& Crum, 1999; Bright, 2008; Steijn, 2008).

However, some controversies on the relationship between satisfaction and performance exist. Some argue that performance causes satisfaction (Porter \& Lawler, 1968). According to this view, satisfaction is considered not as a cause but as an effect of performance. Differential performance determines different rewards as well as recognition under the context of incentives, which in turn produce different levels of satisfaction. Furthermore, rewards or recognition constitute a necessary intervening variable and thus satisfaction is considered to be a function of performance. From this perspective, good performance may lead to rewards and/or recognition which in turn lead to satisfaction. This formulation then might show that performance causes satisfaction. 
In contrast, at the theoretical level of Vroom's (1964) model, “job satisfaction reflects the valence (attractiveness) of the job". Its follows from his theory that the force exerted on an employee to remain on the job is an increasing function of the valence of the job. In the idea of that management has discovered that there is greater production as well as greater profit when employees are satisfied with their jobs. It also reflects the popular belief that 'a happy worker is a productive worker', thus it is far more pleasant to increase the satisfaction of workers than to deal directly with his/her performance when a performance problem exist. Therefore it is more acceptance of the "satisfaction causes performance".

Even though there are some controversies on the relationship between satisfaction and performance, the performance-satisfaction idea still represents an important departure from earlier views about the relationship between these two variables. Moreover, it is noteworthy that human relations, not without some qualification, postulate that high levels of satisfaction would result in high levels of performance.

\subsubsection{DIAGRAM SHOW THE LINKAGE BETWEEN INCENTIVES, JOB SATSFACTION AND WORK PERFORMANCE}

Financial

Incentives

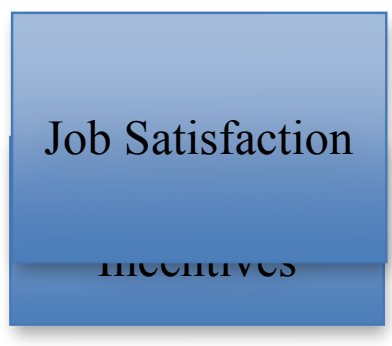

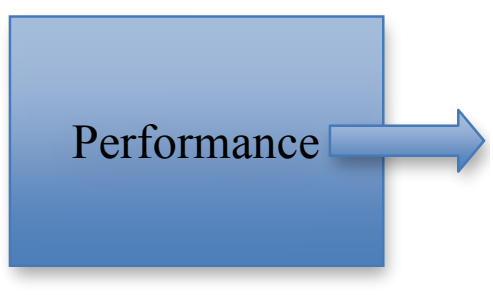

\subsection{SUMMARY}

Based on the detailed review of literature, it could be concluded that incentives were used as motivational tools to encourage individuals or groups of people, to fulfill and satisfy their needs in an attempt to achieve greater performance and increase overall productivity. In the context of employee motivation, the concepts of incentive could be rewards and recognitions. These two components are inter-linked and sometimes complement each other so it is complicated to separate them. In addition, the effectiveness of incentives for individuals and groups differ in how much they 
perceive and are willing to contribute to an organization. It is not only in what they do, but also in how well they do it. This means that the overall performance of an organization depends to a large degree on the productivity of individuals and groups within the organization.

In the public administration, research studies of job satisfaction have focused on distinctive aspects of the public sector working environment, particularly the correlation between organizational behaviour and performance. Apart from personal and job related characteristics, a number of elements, such as pay, promotion, job stability, supervision, management, work group characteristic, organizational structure and policy are considered as key elements to determine job satisfaction (Rainey, 1997; Bright, 2008; Su \& Bozeman, 2009). In public service motivation research studies, job satisfaction is considered as a result of public service motivation as the particular work related environment seems to be able to satisfy the needs of both individuals and groups under the context of motivation. It is also found that the higher willingness of public service by the individual, the higher satisfaction level on the work as well as the higher level of performance (Rainey 1997).

There are an array of definitions for incentive, motivation and job satisfaction. The literature covered has provided us with an understanding of the complexity of three variables for this research: incentive, motivation and job satisfaction. To enhance organizational competiveness and to achieve sustainability, there should be a clear and well-balanced formula that could be used to balance the three variables as mentioned above. The discussion on incentive, motivation and job satisfaction in this chapter has laid the foundation and will be the basis for discussions throughout the entire study. 


\section{RESEARCH METHODOLOGY}

\subsection{INTRODUCTION}

The main purpose of this chapter is to identify a clear methodology approach that assisted the entire process of the research, which was to explore whether there is a linkage between employee incentives and quality performance in the particular context of a Cambodian public organization. As a part of the theoretical body of knowledge, the previous chapter provided a comprehensive literature review of different variables that could be explored for this study. Also, based on the literature, the research model was designed to identify the key issues of concern to the research questions. In an attempt to construct the appropriate model and respond effectively to the questions, both theoretical and practical approaches will be applied. From the theoretical approach of the research, qualitative research processes are implemented. Put simply, the theoretical framework will be incorporated into the research methodology in an attempt to provide a clear structure and outline the key processes of the research. In addition, different essential steps of the research method were implemented including research phenomenology in order to capture these complex situations, extract the information and develop a comprehensive theoretical perspective. Furthermore, this research will take an inductive, qualitative and exploratory approach. Therefore, the phenomenology is the appropriate methodology for this research since the study of phenomena is "focusing on individuals' direct awareness, experience and personal perception rather than socio-historic context or even the supposed reality of an object" (O'Leary, 2010, p. 120). Moreover, grounded theory's framework will also be incorporated into the methodology to provide a structured and systematic blueprint for this research process. Since the primary purpose of this exploratory study is to identify whether there is a correlation between employee incentives and employee work performance. In this study it will be assumed that employees with high motivation, satisfaction and recognition usually perform well.

\subsection{QUANTITATIVE AND QUALITATIVE RESEARCH}


Quantitative research is a kind of process that provides a means for testing objective theories by examining the relationships among variables (Creswell, 2009). These variables, in turn, are operationalized so that they can be analyzed and measured by using various statistical procedures. Quantitative research methods are more formal, objective, structured and scientifically based than qualitative method (Malhotra et al., 1996). Quantitative research methods usually involve larger, more representative samples than those used in qualitative research. The data obtained are subjected to quantitative analysis from which inferences can be drawn about the population.

Quantitative research refers to the group of inquiry method that involves the use of numeric representations of the world (Yoshikawa, Weisner, Kalil \& Way, 2008). In contrast, qualitative research studies people's experiences in their natural setting in order to interpret phenomena in relation to the meaning participants ascribe to them. Also, qualitative researchers use a wide range of interconnected interpretive practices in the hope that they can gain a better understanding of the subject matter (Denzin et al., 2008). A similar finding has been defined by Denzin and Lincoln (2008, p.4) a qualitative research approach is situated in a particular context and it locates the researchers in the world where it consists of a set of interpretive, material practices that make the world visible, "The practices transform the world". Meanwhile, Creswell (1994, p.1) defines qualitative research as an "inquiry process of understanding a social or human problem, based on building a complex, holistic picture, formed with words, reporting detailed views of informants, and conducted in a natural setting". It can be considered as a field of inquiry in its own right, which cuts across disciplines. The author further states that qualitative research is a means for identifying and understanding the meaning individuals or groups ascribe to a human and social issue. Qualitative research also refers to "research that does not use numbers" and usually involves an inductive study (Seale, 1999 p.119). Morgan and Smircich (1980) described qualitative research as an approach rather than a specific set of techniques. The authors argued that its appropriateness depends on the nature of the phenomena being explored.

Meanwhile, a research methodology is a structured guideline or activities to produce a reliable and valid result for the research (Mingers, 2001). In some research inquiries, the researchers have to address some issues of whether the study will 
follow a qualitative or quantitative research method. Generally, there are two main methods of the research and each method is employed and applied based on the reality of the research. The qualitative and quantitative debate has been illustrated within two apparently opposed epistemological positions, which were known as the experimental or positivism approach (Richardson, 1996). Some authors have contrasted the assumptions of the two approaches. They stated that each approach is governed by a different set of genres (Guba \& Lincoln, 1989). Another study has been conducted by Becker (1986, p.122) both qualitative and quantitative researchers "think they have something about society worth telling to others, and they use a variety of forms, media and means to explore and communicate their ideas and findings". Each of the two approaches has its own preferred forms of representation, interpretation and evaluation. Accordingly Bryman (1988, p.3) adds to this qualitative versus quantitative debate by suggesting that, "the distinction between qualitative and quantitative research is really a technical matter whereby the choice between them is to do with their suitability in answering particular research questions".

There are both advantages and disadvantages of using quantitative as a research method. The benefit of quantitative is the research data strives to be objective, to conduct results of fact and reason. This research method is quite often seen with hypothesis testing studies and for this reason the quantitative design has often been relayed as the true scientific method of research (Ghauri, 2005). In short, the advantage of a quantitative research method is to allow the researcher to quantify the respondents' answers toward a certain hypothesis, variables and some specific demographic data in order to come up with a statistic comparison and conclusion. However, there are some negative points concerning quantitative research method. Quantitative method is mostly based on well-structured and already decided questions, which all the respondents will be asked following the designed question. All the information used is to narrow down the area of interest and all respondents will be given the same questions. Thus, by using quantitative method, researchers are unable to get detail information, it also lacks the ability to understand the respondents' points of view.

Qualitative research method, on the other hand, has a stronghold when investigating respondent feedback, feelings, opinions and other subjective variables. For example, 
during the interview, both interviewer and interviewee can take part in each other's thoughts through their own experience and valuation. Instead of a wide range of sampling, the study often intends to conduct reach in-depth and to explore a problem or phenomena in its natural environment to achieve understanding (Ghauri, 2005). Qualitative research is mostly used when the researcher wants to conduct a specific research which cannot be measured in numbers, and preferred and the research aims to get profound understanding of a particular area instead of a total overview also based on the studies conducted by Hamilton, Vidich and Lyman (1994) qualitative research method is a new strategy or framework for doing social research.

\subsection{RESEARCH DESIGN}

In an attempt to achieve a total understanding of the chosen research topic this research was mainly drawn from the qualitative research method. This research method aimed to figure out the importance of employee incentives and their effect on quality performance particularly in a public organization in the context of Cambodia. Instead of conducting quantitative method by initiating numerous respondents to the research questions, in-depth interviews were conducted with a small group of people, which were selected from a Cambodian public organization - Cambodian Investment Board - CIB under the Council for the Development of Cambodia - CDC. The reason behind selecting a single case study is often that the research object is critical and the situation is the best match to reflect the aim of the research. Since the researcher is working for the above said organization, there are many advantages in affiliating and collecting data. It is also the simplest and least cost alternative compared to other methods of research. However, it is important to notice that one single case study could not generate conclusions for a population, it was only possible to observe the behavior at the selected organization and make conclusions related to the theories (Yin, 2006).

The opinion was that the main purpose of our study could not be achieved through a survey, but interviews with a number of people that could gave us more detailed information and with additional questions we could gain greater knowledge. However, at some points, the researcher utilized knowledge obtained from various articles written on similar topics conducted in previous research efforts. Qualitative method of this research increased the likelihood that we could retrieve the true 
opinions, feelings and feedback of respondents toward employee incentives and quality performance.

Therefore, the framework used in this research is divided into the following five steps:

1- The researcher identifies the general subject that she/he wants to investigate. In this case, the effectiveness of employee incentives on the quality performance is the subject.

2- The researcher constructs some concepts and processes in order to guide data collection. Those concepts and processes are drawn upon the sources from relevant literature.

3- The data collection process was based on recorded face-to-face interviews.

4- The collected data are transcribed into a written document. Then the researcher examined the document in great detail in an attempt to identify the common pattern and major themes.

5- Lastly, the emergent themes and pattern are then used to develop useful theories, insights and learning, which relate to the research questions.

\subsubsection{CHOICE OF SELECTING ORGANIZATION}

Selecting the most suitable organization for conducting research is preferable for all researchers. Firstly, my original plan was to undertake the research within some public organizations in Cambodia as a case study. I attempted to assess the functions of employee incentives and the positive on quality performance and working environment within the selected organizations. However, this original plan did not materialize because of some research difficulties, for example, the scope of research was quite big and might prove unachievable within the allowed timeframe. And I felt uncomfortable about getting access to data from those public organizations in Cambodia. With a series of consultations with my supervisor inline with my current status as employee working at the Cambodian Investment Board under the Council for the Development of Cambodia, the decision was made to choose the above said organization as a case study instead of selecting different public organizations for the research. It is worth noting that the Cambodian Investment Board is one of the key players among other boards. There are three boards that make up the Council for the

Development of Cambodia: Cambodian Investment Board; Cambodian 
Rehabilitation and Development Board; and Cambodian Special Economic Zone Board.

\subsubsection{DATA COLLECTION}

The means of collecting primary data is mainly based on qualitative interviews. Qualitative interviews are defined as interviews "whose purpose is to gather descriptions of the life-world of the interviewee/s with respect interpretation of the meaning of described phenomena" (King, 2004a p.11). Qualitative interviews are amongst the most common data collection method in qualitative research. According to Mason (2002) qualitative interviews can also be used as one of several methods to provide an extra dimension, which enables the researcher to explore the research questions from a different angle. This technique is useful particularly when the aim of the research is to develop depth and further understanding.

For this research study, qualitative interviews were used and carried out with selected participants from a Cambodian public organization namely Cambodian Investment Board - CIB under the Council for the Development of Cambodia CDC. In addition to this, secondary data from relevant articles was also used which were useful to support our findings. To assist the interview process, an interview guide containing structured questions was developed and provided to the selected participants for an interview. On one hand, the information solicited from this instrument could help the researcher to get deeper knowledge concerning the research questions. On the other hand, the choice of this instrument was developed because it was considered as the most suitable method for exploring data, which dealt with the topic in depth. In-depth interviews were conducted through face-toface discussion and interaction. All interviews were recorded with an audio-recorder to ensure information and data provided by the participants were accurate and correct. In short, interviewing was the most appreciated method for generating data based on participant feedback, opinions and ideas. The participants had opportunities to express and expand his/her ideas, explain their views and identify what they considered to be the essential factor that affected their work performance.

\subsubsection{SAMPLE SIZE}


In relation to the research, the main objective is identifying the importance of employee incentives and their effect on quality improvement in a public organization. Due to time and budget constraints, the participants were only selected from the Cambodian Investment Board - CIB under the Council for the Development of Cambodia - CDC. In order to gain a wide range of knowledge on the research topic eight participants from different departments were selected for in-depth interview. The interview itself took approximately 60 minutes including introduction and some explanation of the research. This research mainly focused on phenomena which meant the data collection process was required to capture a rich understanding of individual's experiences in relation to a particular phenomenon rather than acquiring statistical data to generalize the whole population. It also meant that the units of analysis and participants are purposely selected instead of randomly selected. In detail, the interviews were conducted with eight employees from four departments of the Cambodian Investment Board: Investment project evaluation and incentive department, administration department, investment information department, and legal department. Most of the employees were at the operational level of the organization, which was much easier to work with compared to higher levels in the public organization. It was decided to interview employees at four different departments because it was hoped that the information provided would differ and could cover most of the research questions.

The initial stage was to identify the key participant from each department to our research. Then first contact was made through telephone calls, email or personal visits to evaluate and ensure the participants can be met the eligibility criteria for the research. Next, an appointment for an interview was set based on the possibility and availability of selected participants in relation to the research schedule and timeframe. In an attempt to ensure that research findings are well represented, diversification approaches were applied. This included selection criteria such as gender, age, background, position and workplace. The selected number of participants should be enough to capture key elements of the research questions. However, more interviews would be conducted if the eight in-depth interviews were not able to obtain sufficient data to produce suitable findings for this research.

\subsubsection{RESEARCH INSTRUMENT}


The main instrument used for this research was the face-to-face interview. The interview questions were designed based on an extensive review of published academic literature concerning the research topic. The researcher conducted interview questions that were semi-structured to allow the interviewees to express their opinions or ideas instead of just answering the questions. This technique provided more in-depth information about their perception toward the incentive system within as well as their expectation toward the entire organization. A qualitative interview is often called semi-structured since the questions are well organized but with some possibilities for the participants to express their thoughts, feedback and manage the direction of the interview. This procedure was generally implemented in an attempt to get more information from people about their opinions and the ways they interpret the questions rather than collecting data from the survey (Blumberg, Cooper \& Schindler, 2011).

In addition, preparation and guidelines were constructed to facilitate the interview process this included timeframe and plan. In order to provoke more interaction and discussion especially to encourage participants to provide more information, a series of key questions and sub-questions were designed under the five main categories. The first category was concerned with personal information, background, skills and past work experiences of participants. The second category was dealt with individual's expectation and requirements toward their current job and workplace. Meanwhile, a series of supportive questions were developed to support the main question. Those included job satisfaction, advantages and disadvantages of working in a pubic organization and so on. The third category was designed based on the individual's perception toward incentives (financial and/or non-financial incentive). It also included an individual's understanding of work performance. The fourth category was developed according to the type and characteristic of each incentive. Also the initiation and implementation of those incentives based on the current work environment of the Cambodian public organization. And the fifth category was developed based on the profound knowledge and work experiences of the participants. This included the alternative incentive scheme in quality improvement of work and some circumstances that incentives are not successful or effective. Furthermore, in an attempt to achieve fruitful information and to keep the entire interview process on the right track, the interview schedule was developed. It accomplished this by providing a clearer guideline as to how each interview should 
be carried out as well as a rough estimation of time that should be spent on each category of the interview questions, so the participants could make an even contribution to each category and the researcher was likely to keep each interview within the specific timeframe - around 60 minutes each. It also provided a clear guideline on how each interview should be carried out and how to handle different or unexpected outcomes.

\subsubsection{INTERVIEW TECHNIQUE}

The interviews were conducted under the semi-structured guidelines in order to provide plenty of time for participants to respond to the questions. By doing this, participants were free to express their own thoughts or opinions toward incentive in general, and more specifically their effect on quality of work performance within the above said organization.

Before conducting the interviews a pilot interview was carried out with other employees also working at an operational level in the legal department of the Cambodian Investment Board. The intention was to ensure all the designed questions were well understood among the respondents.

\subsubsection{DATA ANALYSIS}

The qualitative data were analyzed using thematic analysis as qualitative analysis procedures. According to King (2004b) thematic analysis refers to the identification of core themes and sub-themes in qualitative data. The text from open-ended interview questions is analyzed using a coding procedure and reduced into a set of key themes and sub-themes through the entire process of data analysis. For this research study, thematic analysis of interview transcripts was implemented in order to highlight common themes of the research. This procedure could facilitate the entire process of analysis to categorize and examine data obtained from audiorecorded interviews. Also it helps in comparing the data obtained from different questions of the research. The most commonly used procedures were applied during data analysis. First, reading carefully through the entire transcripts. Second, each given response from the interview was broken into smaller, meaningful pieces of information. Then the researcher had examined that information in further detail in order to figure out the key variables that emerged from the participants' responses. This procedure was highlighted and underlined for the next step. Last, those labeled 
and highlighted points were grouped and the similarly coded chunks of coded text were put together to form categories, core themes and sub-themes. This process allowed the researcher to identify different variables, which merged from the transcribed data and grouped them into specific categories. We did that by closely managing and editing all the grouped cards under each category of processes in order to figure out the relationship of the emerging variables within each category. For instance, a variable that kept on reoccurring in each group under a specific category should illustrate a strong relationship. (Leech \& Onwuegbuzie, 2007). This analysis method also combined the relevant literature with the relationship and themes of each category that were closely examined in the previous stage in order to generalize the research findings.

\subsection{ETHICAL CONSIDERATION}

The researcher can ensure that the entire process of our research was performed under ethical guidelines. To make sure all selected participants are well aware of the research objective, process and the outcome, we provided them with all research related information. This included the physical and emotional risks associated with the research. Participants were entitled to know about timeframe, scope, involved parties, implications as well as contributions of our research. Also participants were reasonable capacity, maturity and free to respond our questions without condition, hesitation, pressure or force. Participants were fully respected and there was no obligation to fulfill our research requirements and they were free to stop participating at any point. Thus, the researcher can ensure that the nature of our research was honest, open and friendly with no intention to harm participants, especially psychological and emotional harm. All information provided was kept confidential. The information collected from the survey was solely used for the research and only the researchers had access to the survey. The information obtained from the survey was analyzed based on the theoretical and practical approaches of the research. All information obtained from the respondents will be destroyed within one year after the completion of the research. More importantly, the approval for conducting research has been granted by the Human Ethics Committee at Victoria University of Wellington - VUW.

\subsection{FORESEEABLE LIMITATION OF RESEARCH METHODOLOGY}


This research might contain some biased material because all selected participants were neither allowed to read the questions in advance nor prepare for the answers. Therefore, all the responses were greatly dependent a on participant's ability especially their knowledge, current and past experiences to answer the questions. Moreover, this was a face-to-face interview based research; some participants were not used to digitally recorded interviews and some were not fully cooperative. As a consequence, it was unavoidable to lose some main points if the participants could not fully understand the questions or felt it was difficult to provide desirable data.

In order to reduce some negative effects, and also to maximize the reliability and acceptability of the data, all main processes were carried out carefully, this began with collecting, analyzing and interpreting data. In addition, in an attempt to minimize the level of bias within the research finding, it was essential to properly organize and review the relevant literature and pull out some relevant secondary data to argue, support and complete the research gap.

Another drawback is that this methodology contained data of an unsystematic and non-scientific nature, which allowed the researcher to get involved and form experiences throughout the data collection process. Therefore, this designed methodology may create some findings that are less valuable or not completely relevant to the research inquiries, which can limit the ability of the data to answer the research questions. In order to reduce these limitations, this research has integrated the grounded theory framework into the research methodology in an attempt to provide a structure and offer systematic data analysis. Furthermore, the repeated themes that were produced by the data analysis methods will be incorporated with the secondary sources of data that were drawn from the relevant literature, in attempt to provide the generalizable findings that answer the inquiries of this research. 


\section{CHAPTER 4 \\ RESEARCH FINDINGS}

\subsection{INTRODUCTION}

Following the discussion of the methodology in the previous chapter, this chapter presents the findings from the study about the importance of employee incentives and their effectiveness in improving quality performance in a Cambodian public organization. The study was intended to explore the types, characteristics and benefits of incentives, either financial or non-financial, in the Cambodian Investment Board/Council for the Development of Cambodia (CIB/CDC). The study consisted of interviews with both males and females from different departments to ensure that the data was representative. Furthermore, most questions were answered concisely and follow-up motivations to answers were provided when the researcher felt the necessity to probe. There was also a strong sense of confidence felt when all the questions were answered. Also the participants led the researcher to believe that they knew what they were talking about.

Based on the literature review in the previous chapter, higher work performance as a consequence of job satisfaction, and job satisfaction can be obtained from various incentives as employee motivation. The result obtained from this study shows a major similarity to the reviewed literature. Even though some were not what we expected, those differences constituted a small percentage in the research findings, which can be shaded light for future research study. Overall, the results of the study were found to be much the same as we expected.

The importance and effectiveness of motivation as well as the correlation between job satisfaction and higher work performance were thoroughly studied and explained in order to show their actual relationship and effect on the organization.

\subsection{RESULTS}

The earliest question in this research is "what does the general concept of incentive mean to employees in the public organization?" This question was developed in an attempt to capture the general picture of incentives in the mindset of employees, particularly public employees. To some extent, respondents can express their thought 
or opinion about incentives through examples or other means. When the answers are grouped, there are about 10 different responses. Among those responses, the three most frequently repeated by respondents were "promotion", " money or other from of benefits" and "various activities aimed at fulfilling employee needs and encourage employees to work harder". The other categories were: gift, appreciation, recognition, respect, flexible working hours, good working environment. These categories generally matched the characteristics of financial and non-financial incentive categories.

The second research question intended to explore the effectiveness of incentives and their correlation with employee's performance. Most respondents responded as following:

The results showed a significant effect of both monetary and non-monetary incentives for better job performance. The selected participants expressed different job dissatisfaction toward the non-availability of certain incentives, which significantly affected their overall work performance. The majority of the interviewees reported that the more dissatisfied they are with respect to the limitation and/or absence of certain incentives for performance, the less productive they would be at work. One respondent did say, however, that though he was not satisfied, it didn't affect his performance. In general, the results showed that providing additional monetary and non-monetary incentives to public employees could improve their work performance and increase productivity.

The third question of research was developed in an attempt to identify the most suitable type of incentives for Cambodia public organizations. The results of the interviews are as follow:

Participants mentioned that both financial and non-financial incentives are suitable to use in Cambodian public organizations. They also expressed that those two types of incentives are extremely important; they complement each other to motivate and encourage public employees to exert more time and effort for better performance and greater achievement. The above responses reveal that employees do not always consider money or other forms of financial benefits when deciding to work for public organizations. Non- 
financial factors such as opportunities for promotion, job recognition, work autonomy, opportunities for development and advancement, are also important.

The next question asked about the perception of public employees of various motivational factors that they valued most. The main theme is "insufficient organizational supports". Furthermore, the sub-theme, which was mentioned more frequently than any of the other themes, was insufficient financial and non-financial support for their efforts and performances. During an interview, most respondents believed that both financial and non-financial support represented how much the organization was willing to support them and were concerned and cared about its employees. Also they considered financial and non-financial support as the motivational tools that the organization should provide to effectively and successfully assist the employees to implement their tasks. The respondents also said that the organization should value employees' contribution and accomplishment by providing some sort of rewards as well as recognition whenever and wherever possible.

From the findings, public salary or wage were the two main forms of monetary support mentioned by the respondents, however, some alternative choices were expressed for example, work allowance, travel allowance, subsidizing monthly telephone bills and so on. The majority of the respondents expressed significant dissatisfaction toward the insufficient monetary support they received. They believed that a satisfying wage is important for employee motivation among other factors. Monetary support was one of the potential factors that encouraged and motivated employees' willingness to make extra effort in their job. Public employees who were not satisfied with their wage levels expected the organization to fill this gap through extra financial support such as pay or wage increases, and providing additional financial support.

"Wage increase is extremely important for me, I am a low level staff, I earn very little compared to others"

"I know the government had envisaged to do more to increase salaries but was advised to limit options to those that could be financed within available resources.........." 
"Salary and others benefits are important, it motivates people to work harder."

Based on the participants' responses, most public employees, in order to cope with inadequate public monetary support (low public salary), engaged in other activities to generate more income while working for the public service. Some participants said:

"I am also working as a part time teacher for one of the private schools in Phnom Penh..."

"My main income is coming from others' businesses, and it is impossible to survive under the government's salary."

"Only government salary is not enough to cover my living cost, thus, I spend time to do other things."

"It is hard to survive on just this small amount of income."

Overall, participant's responses emphasized the importance of financial support among other factors. Financial support has also played a major role in fulfilling the basic needs of public employees, encouraging and motivating them to work harder and perform better, which ultimately increases organizational work productivity.

Even though monetary support appeared to be an important motivational factor among public employees, non-financial support, which emerged as a key theme, was repeatedly mentioned during the interview. According to participants' responses, non-financial supports were considered one of the effective motivational tools for better efforts, increased satisfaction and greater work performance. Non-financial support was grouped under two main categories: job related characteristic support and workplace support. In general, job related characteristic support concerned the degree to which the job provides opportunities for personal development and growth, job autonomy, responsibility, flexibility of work, job enrichments, challenging work, ownership and so on. According to the data, some participants expressed job dissatisfaction while others expressed some negative points such as poor job related supports. The details of these negative aspects will be emphasized as follows.

\section{(The absence of job related supports)}

The participants identified numerous and varied job related characteristics that they believed motivated poor performance and job dissatisfaction. Some negative points 
of job related characteristics that emerged in the research data were reviewed and reported as below:

"Opportunities for promotion" was a sub-theme under the job related characteristic supports. In the public sector, promotion was a kind of job recognition and reward with no or little financial implication costs to the government. The analysis indicated that public promotion was commended among others factors in the public organizations especially in $\mathrm{CIB} / \mathrm{CDC}$. Participants said that promotional opportunities in a public organization were limited and were unsatisfactory compared to private or profit oriented organizations. Some participants said:

"I have been working in the public service sector for many years, but my position remains the same."

"My knowledge, skills and work experience deserve to receive some opportunities for promotion."

"A chance for advancement is extremely small."

In addition, job autonomy was mentioned during an interview. Some research participants expressed that they have little authority to decide what they will do or when they will finish their job. Their comments show there were some differences between public and private organizations. In public organizations, people work with limited discretion and independence. Most tasks need to be done with direct supervision and control. Meanwhile, time allowance and resources are limited. Enforcement sometimes is inevitable especially when the assigned job or project seem to be complicated or unsatisfactory. However, some other participants responded that they had some degree of autonomy over their job. Those who think they have the authority to decide how to do their jobs are likely to agree that they have the authority to decide when to do it and/or when to finish it.

Job enrichment was another sub-theme of job related characteristic supports. The research participant mentioned about being discouraged and demotivated with low levels of job enrichment. Based on the participants' responses, job enrichment in public organizations can be interesting work, having an interest in the job, job diversities, being able to take something to completion from beginning to the end, different work requirements, various conditions associated with the job, and so on. Even though there were some good points such as occasional new projects, resources 
and work related materials, overall, the participants elaborated that they were demotivated and dissatisfied with the limited job variety, meaningless work, not interesting and irresponsible workplace environment together with insufficient resource and workload pressure. However, some participants expressed some thoughts about having some duties and responsibilities for the current job, positive feelings and getting a lot of self-motivation from the work and seeing the fruitful result of their efforts. These two contradicting findings will be discussed further.

In regard to "unchallenging work", participants mentioned implementing existing projects, routine jobs, everyday work problems, no opportunities to gain new skills and knowledge as some of the factors. They emphasized the overall meaning of unchallenging work through "it gives me less opportunities for challenge", "we cannot do things without initiative and creative ideas", "sometimes we need to adapt to those problems, otherwise we cannot get the thing done", "I have to try to think of more effective ways to do things, but it is useless", "it's times consuming", "it's complicated to deal with sometimes", "it just routine work". Some respondents stated that they preferred challenges in their area of expertise, knowledge and skills. They also mentioned a sense of encouragement, fulfillment, accomplishment and self-satisfaction as what made a challenging work environment.

Another sub-theme of job related characteristic support was "opportunity for development and growth". Opportunities for development and growth were frequently mentioned during the interviews. The participants felt that they were provided with limited opportunities, compared to the private sector, to develop themselves through workshops, in-house training, and various capacity development programmes. The majority of respondents addressed that they had been given some opportunities to attend seminars or training programmes but those were less interesting and time consuming. Some participants elaborated that training does not always have to be directly related to work; it can also be related to personal strengthening of employees or at least providing some escape time from daily routines and stressful work. One participant said:

"I had been sent to the academy of public administration to take a foreign language course, regardless if it is relevant or irrelevant to the job." 
After participating in several training programmes, they felt more comfortable and confident toward the jobs.

The research participants also acknowledged that training plays an important role in motivating employees and preventing them from failing, and declining work performance due to a lack of skills, knowledge and abilities. Overall, most participants strongly required for various opportunities for capacity development and advancement.

"Over job responsibilities" was also a sub-theme of job related characteristic supports. According to the responses, some participants disagreed with the arrangement as well as designation of department managers. They were sometimes assigned special tasks or projects, which were not related or were beyond their abilities and skills, and sometimes given tasks with more duties and responsibilities than usual. Although it might be good that employees had to perform a variety of tasks that allow them to use different skills and knowledge rather than doing the simple and repetitive everyday tasks, it can sometimes produce a negative feeling or be counterproductive if those tasks are quite big and unusual to deal with.

Some research participants commented that there was no mechanism such as monthly or quarterly meetings among employees' particularly low-level staff. Subordinate staff were seldom invited to a meeting or to express their opinions in informal settings. This shows that the degree of involvement or staff participation in the public organizations was not adequate. Some participants felt that participation through expressing ideas in decision making can show their idea are valued and they are given the opportunity to affect the work process and to determine the outcome of an organization. By doing this, it helps to make their job more interesting, meaningful and increase interaction between supervisors and co-workers. Furthermore, according to the responses, employee involvement in decision-making process not only can serve as a motivator but also as a training tool which prepares and develops employees to be a future leader or manager in the organization. Furthermore, such kind of employee participant not only leads to a cooperative work atmosphere, but helps organizations to benefit from the knowledge and skills of employees whenever and wherever possible. 


\section{(The absence of workplace support)}

Insufficient workplace support contributed to the impact of work performance, which led to job dissatisfaction. The sub-theme "workplace support" here was categorized into three groups: operational support, co-worker support, and management support. Based on participants' responses, workplace support was defined as the degree to which the workplace provides its employees with various kinds of support to successfully and effectively implement their jobs. Such support can be recognizing employees' contribution and achievement and more importantly providing psychological and emotional support whenever and wherever required. Overall, workplace support represents a perception by employees that the organization is concerned and willing to care and support them when required.

In regard to operational support, the research participants revealed that some operational constraints generally existed in the Cambodian public organization particularly the $\mathrm{CIB} / \mathrm{CDC}$. The constraints were viewed as the degree to which public employees have to carry out their tasks under the conditions of abundant and heavy workloads, limited time, and with insufficient resources. According to the research findings, three sub-themes emerged from the full range of participants' comments: "workload pressures", "times constraints" and "resource constraints".

With regard to workload pressure, the research participants commented on tough and busy work conditions and not being able to concentrate on particular tasks or projects. Some reported "being overworked", "getting busier and busier" "the workload is extremely impossible". In regard to resource constraints, the participants repeatedly commented on a lack of technical support (IT support or others' work related to technical support), insufficient resources including limited working space, shortage of office supplies, stationery, transport, and sometimes not enough money to finish the project. Some research participants commented that they are frustrated by not having the right quality and quantity of resources and/or equipment for their job. While others said that the variety of resources, diversity of job and status of the working environment was important in their decision to work for the organization. Therefore, workload pressure and resource constraints are one of the key affects toward employee motivation and job satisfaction in the CIB/CDC. 
When talking about time constraints, the participants talked about being hurried, rushed to the deadline, not enough time to finish work, no extra time to review or edit work in detail. Some direct quotes from participants were "I don't even have time to scratch my self", "sometimes I need to bring those tasks back home in order to meet the deadline". Overall, workload pressure, time constraints and resource constraints were viewed as insufficient operational support to facilitate and assist employees' performance in the workplace.

In regard to co-worker support, it was separated into two small themes: individual support and group support. Talking about individual support, the respondents expressed a negative feeling toward interpersonal relationships among employees in the organization. And such interpersonal relationships were expected to exist in the form of being approachable, respectful, concerned, caring and other attitudes. Participants also commented about "very minimal communication between employee and employee". Poor communication was a significant problem in knowing and understanding the direction and goal of an organization and how individual's efforts are linked in order to meet the organizational goal. Individual shirking was mentioned during an interview. Participants expressed some different aspects of negative feelings caused by co-workers such as annoyance, anger, and depression, lack of respect, embarrassment, helplessness, disappointment, stress and others. Coworkers' behavior was also frequently mentioned during the interview. Participants had identified a wide range of co-workers' behavior in the workplace. The participants referred to negative behavior like "delayed or unfinished work", "always coming up with several excuses when tasks were not finished on time", "not putting in their best effort when they ought to", "not really interested in the job", "showing no commitment", "very negative about the staff and task", and "irresponsible, lazy and selfish".

Group support was generally referred to as the culture of helping each other in the group, working as a team, respecting and treating each other as family members, sticking together and cooperation. Regard to group support, research participants felt demotivated and dissatisfied with the teamwork environment in their organization. The teamwork environment as commented on by public employees were negative toward other members in the organization and not being helpful or cooperative. Particularly, not being helpful and coordinating with one another reflected a low 
level of co-worker support and thereby indicated a negative working atmosphere as well as job satisfaction. Furthermore, the research participants described their coworkers as lacking "consideration and cooperation" and "responsibility and accountability" some said that "most employees do their own thing" and "won't cooperate with others". These negative characteristics were perceived to impede their willingness as well as various opportunities to engage with group-work behavior. Based on the participants' suggestions, co-worker support could exist in various forms with different circumstances. For example, helping other members to achieve their work objective, helping others who have been absent, sharing expertise and knowledge, displaying care and concern, showing respect and consideration toward other co-workers, giving advice and so on.

Management support is commonly about management's respect, trust and confidence in staff, valuing and recognizing employee accomplishment, equal treatment between employees as well as between employees and supervisors. In addition, it was about the degree to which the supervisors or managers provide any means of technical, physical or emotional support that enables subordinate staff to believe that their supervisors or managers are concerned and care about employee participation, contribution and well-being.

According to the participants' comments, management are supposed to adopt an employee oriented management style and demonstrate a positive regard for others to the greatest level if possible. Showing some courtesy including a smile, the use of appropriate language, respecting and valuing others, showing an interest, talking to employees on certain things that are far beyond the employees' abilities, and generally being helpful. According to one interviewee, "showing positive feelings and interest in all employees were significantly assisted in understanding employees and grasping the working environment in the organization". Another research participant commented that "organizing any event or party and inviting employees to join also supports the effort, as well as boosts an employee's self-value, selfappreciation and having a great feeling toward the organization".

One of the remarkable themes under the lack of management support was "autocratic management behaviour". Generally, autocratic management behaviour related to acts by the supervisors or managers in the organization that negatively affect the 
subordinate staffs' emotional or psychological state, and sometimes makes it difficult for the subordinate staff to perform their duty. There were some comments on the psychological affects caused by autocratic behavior of workplace supervisors or leaders. Participants' comments covered the state of being treated unequally and unreasonably, bad supervision, lack of respect from supervisors, unsupportive management behavior, showing no trust and confidence in employee's abilities, their performance and accomplishments, and showing no consideration and concern toward the well-being of employees. Regarding the autocratic behavior of leaders, participants commented that they perceived these management behaviors as unjustified and unfair. In addition to this, they felt that their contribution and efforts were being ignored and sometimes devalued, and that this affected their sense of encouragement and motivation as well as satisfaction.

In addition to autocratic management behaviour, there were some impediments mentioned by research participants such as excessive supervision (controlling all employees' activities, and sometimes interfering, obstructing and undermining employees' performance), poor interaction and communication from the manager, being unapproachable and non-consultative, being inaccessible, and sometimes not being open to the views of employees and so on.

"Excessive supervision" also emerged during an interview and was considered a subtheme of autocratic management behavior. Some participants perceived that excessive supervision sometimes was considered an exercise of control, which is counterproductive toward job satisfaction. As the quotes below revealed, close and frequent supervision was sometimes perceived as controlling, monitor rather than being personal and supportive. Employees criticized the management style used by managers especially the irregularity and frequency of supervision in the workplace.

"Close supervision is unhelpful, they remind you of the working procedures, roles and control you all the time."

Some felt that their management lacked encouragement and insufficient consideration of staff opinions, as the employees did not feel sufficiently supported and recognized by their superiors. In other words, management tended to contribute 
as little as possible to develop and enhance employees' efficacy. The unpleasant working relationship between the superiors and subordinates had had an extreme negative psychological and emotional effect on the participants. Some participants believed that their leader's actions impeded the overall ability to effectively and successfully perform the job since the employees were not provided with a clear understanding of the roles, a clear guideline of what the supervisors expected from the subordinate staff.

Based on some suggestions raised by the respondents, apart from regular and frequent supervision, different productive ways and forms of supervision can be applied, in that supervision can be in the form of encouraging, being supportive, need oriented, participatory and should provide some feedback on work related problems and give solutions in a timely and direct manner. Through an encouraging and supporting attitude, managers can enhance the self-efficacy of employees and thus foster individual commitment to achieve organizational goals. Even though, the impediments of excessive supervisions were less extensive compared to other factors, but it's still mentioned frequently among research participants. Overall, these impediment comments highlighted the psychological, emotional and functional effects of autocratic management behaviour, which have a potential impact on the interpersonal relationships between management and subordinate staff. Also, autocratic management behaviour and their actions impeded employees' ability to successfully and effectively perform their tasks and meet their expectations.

Even though, there was a dominant theme concerning the negative workplace supervision as well as management behaviour, some respondents acknowledged that supervision is desirable and useful to some extent. It helps employees work performance, to avoid mistakes, to keep the job on track and to update knowledge and skills. When individual concerns are taken seriously, supervision provides ways of doing things and shows the sense of concern and care. A small number of research participants seemed to be satisfied toward the general operation and management in their workplace.

"Poor interaction and communication" also emerged from the interviews and showed that public employees were unhappy with management behaviour particularly the 
low level of interaction and communication between superior and subordinate employees. Despite this being a less significant factor the respondents still considered that good interaction and communication between superiors and subordinate staff were extremely important in improving individual and/or group performance, to avoid misunderstanding, to avoid work related risks, and overall to improve the work environment. When personal needs or concerns existed among public employees, close interaction and good communication between managers and employees can provide feelings of concern, care and appreciation. According to the respondents' suggestions, there are many effective ways in improving these negative behaviours. Apart from a more frequent and regular visit, managers can develop more activities or events that enable both managers and employees to be a cohesive group, to be involved and interactive.

Under the main theme of "insufficient management support", the research participants also commented about the "lack of recognition and appreciation" especially of employees extra efforts and contributions. These comments included feedback on employees' performance. In regard to feedback, the result showed that management does not always recognize good work done of employees. The result revealed that some respondents would appreciate feedback and appreciation for work achievement. According to the obtained result, some suggested that job recognition in the form of a certificate or an appreciation letter were much needed among public employees. The appreciation letter, it might be used as a record of great achievement or to add to their curriculum vitae. Some responded that either formal or informal recognition for a good job was important for their career development and advancement. It also contributed to the creation of a working atmosphere that employees valued. It has great potential to motivate employees without requiring financial resources.

Public employees wanted some feedback especially positive feedback regarding their performance in the workplace. It was related to the on-going process particularly between management and employees in the organization. Feedback could provide a direct way of communication to eliminate uncertainties and solve various work related problems. In addition, it could adjust or correct poor performance and praise contributions and effort as well as employee achievement. According to the 
responses, feedback could be positive and negative and both have great potential impact on the overall performance of employees. Feedback was considered an intrinsically non-financial support that was expected to motivate employees because at least they could get information about how well their job was with regard to the management expectations or organizational objective. Based on participants' comments, feedback on employees' work performance also served as an indicator to show employees how well they performed, how close they achieved their goals or whether there was anything that they needed to improve on. Feedback can take the form of formal or informal expressions. In other words, feedback can be in the form of verbal praise or written appreciation. The participants acknowledged that some negative feedback might be needed in some circumstances especially when employees do not follow work procedures or work requirement. One research participant said:

"Even though it's sound bad, but I may need some information or guidelines, if I don't fully understand the tasks"

From the viewpoints of research participants, employees were frequently criticized by managers, and sometimes corrected their mistakes but did not easily or frequently express a positive feedback like appreciation or recognition on employees' performance. The feedback that employees received from their managers usually centered on shortcoming of work done or mistakes related to technical aspects and it was hardly appeared to be supportive or constructive feedbacks.

"Time and effort go unnoticed, whereas, employees shortcomings and mistakes are noticed immediately."

The research participants further revealed that the level of recognition practices in the form of verbal or written appreciation to encourage success as well as positive behavior of the employee within the researched public organization was low, and sometimes ignored by management. And there was no mechanism such as appreciation letters or bulletin board to promote employees best performance.

"I work hard, but I never receive any praise or appreciation letters from the head of department."

"It is good to be like this, not to be blamed."

"Criticisms from leaders are unavoidable." 
"Unequal and unfair treatment" was another theme to emerge from the interviews. Some research participants expressed a low level of satisfaction toward unequal and unfair treatment among employees in the public organization. They also commented that there were a few problems regarding staff arrangement and motivation, and unfair allocation of opportunities for overseas training programmes were among those. Unlike local training programmes, access to training and further qualifications overseas was limited and it was granted in line with close relationships or connection bases. The arrangement and designation was not based on capacity or job specification requirement. This can have detrimental consequences for the motivation effect of training as a tool for human resource development.

Among those, there was an unexpected theme, which emerged from the data analysis. One participant revealed that he was strongly committed to his job, motivated and tried to maximize his effort in order to achieve the common goal of the organization even though the level of job satisfaction was still low in the organization. Even though the number of responses in regard to this unexpected theme were minimal compared to other sub-themes in the findings, they offer material for further investigation and discussion.

\subsection{SUMMARY OF RESEARCH FINDINGS}

From the above findings, it can be inferred that public employees in the organization enjoy fixed wage levels regardless of their effort, extra contribution and work performance. There is no performance based reward system or mechanism regarding recognition of best performance. Thus, there is almost nothing to motivate public employees of Cambodia to perform to their best ability in their job and to reinforce their positive behaviour in order to achieve individual, group and organizational goals. Therefore, it is important especially for Cambodian public organizations that some kind of incentive mechanism should exist to motivate public employees to contribute more, to do more than what is expected from them and to recognize their accomplishment. It's also worth noting that because human needs vary from person to person and across a life span, incentive needs will vary in their impact on motivation depending on the person and the stage of life at which they are. Three variables affected the process of motivation: individual characteristic, job characteristic and workplace characteristic. The effectiveness of employee incentives also depends on one or more of these variables. 
The research findings also found that a group of public employees at the Cambodian Investment Board under the Council for the Development of Cambodia (CIB/CDC) had expressed substantial differences in their dissatisfaction towards the absence of organizational support. It represented a perception by public employees that the organization was willing to support and were concerned about its employees. This organizational support mainly referred to certain of type incentives (financial and / or non-financial incentives) that may affect their overall work performance and workplace productivity. This group of public employees differed significantly in terms of the dissatisfaction due to the non-availability of both financial and nonfinancial incentives. And mostly, the obtained results seem to show that the more dissatisfied they were with respect to the non-availability of both financial and nonfinancial incentives for their performance, the poor performance and less productivity they would achieve at work. In this regard, it is essential for the organization that a system of reward and/or recognition as motivational tools should be implemented to motivate employees to exert more effort and produce greater outcomes. According to the obtained results, two main types of incentives: (1) financial incentives and (2) non-financial incentives were significantly addressed and strongly required by the research participants.

To sum up, the level of satisfaction of the employee incentives particularly financial and non-financial incentives in the above said public organization were low. Among other factors, wage satisfaction was most desired among public employees, followed by intrinsically job related characteristic such as management supports, co-worker support, operational support and so on. Although the feedback on organizational performance did exist it tended to be negative feedback such as blame and criticism. Even though, there were some good comments concerning job diversification and enrichment as well as management supervision from particular departments, the level of dissatisfaction far outweighed work and workplace satisfaction. 


\section{CHAPTER 5 \\ DISCUSSIONS}

\subsection{INTRODUCTION}

From a human resource management perspective, when individual or group performance is lower than an organizations' expectation due to the disruptions, the organization may generate different approaches to boost employee work performance and increase productivity. All organizations, regardless of whether they profit oriented, non-profit or public organizations, need highly motivated employees to be effective and efficient in their operation. Employees who are motivated to perform effectively and successfully toward the achievement of organizational goals are one of the key factors for the success of an organization. In regard to the public sector, motivation is significantly important because efforts to improve the entire performance as well as the overall work productivity of government institutions largely depends on the ability to successfully motivate public employees.

Talking about motivation, one of the first things and most common that comes to mind is the concept of incentive, which refers to any means that encourage and motivate employees to work harder and to do better. Even though there are some contradictions regarding the use of incentives, overall, both public and private organizations greatly benefit from the fruitful result of incentives. It is well understood that incentives are developed in an attempt to motivate employees to work harder, and to achieve individual and organizational goals. In other words, by using these incentives, the organization tries to align the objective of the employees with the interest of the organization. And the development of various employee compensation schemes is expected to engender a greater sense of responsibility, and a greater sense of belonging to the organization which in the end could motivate people, and encourage them to exert more time and effort aimed at attaining greater performance.

This chapter will mainly discuss the result of research study, which is relating to the investigation of the relationship between incentives and their consequence on overall work performance. In light of the general findings, the existence of insufficient support in the above said organization was considered the most important point for 
motivating public employees. Insufficient support, which was repeatedly mentioned in the research findings, were classified into two categories (1) financial supports and (2) non-financial supports and both will be thoroughly evaluated and discussed in the following section. In addition, our discussion will be guided and supported by the detailed arguments from the literature review and other past research studies on employee incentives.

\section{(Financial Support)}

According to the majority of research participants, it could be implied that the performance of public employees could be boosted to higher levels if the organization provides them with better financial support than they were receiving. According to Maslow's hierarchy of needs, physiological needs are generally known as the most basic needs of people for supporting and sustaining their lives. The point is that without adequate support especially financial support people will hardly be able to contribute much time or effort toward work and workplace (Maslow, 1943; Lathan \& Ernts, 2006; Mager \& Sbilia, 2010). Herzberg (1966) argued that when motivators are present, employees are highly motivated to excel at their work with higher satisfaction. In contrast, when motivators are decreased or absent, workers are usually neutral toward work. Based on Herzberg's theory of motivation, monetary incentives may have the power to drive those employees to exert much time and effort in their work. This is consistent with the findings of this research which found that employee satisfaction was strongly related to employee's pay satisfaction, which is evidence that monetary incentives are a motivating factor. Benett, Yongmei, Stepina, Goodman and Treadway (2006) have also indicated that pay and other benefits that are hygiene factor also appear to be of importance to improve job satisfaction and retention. Even though some employees are intrinsically motivated, it is possible for the organizations to lose their employees if they do not pay more attention particularly to pay and benefits.

In addition to this, even though other forms of financial supports are available as discussed in the literature review, most public employees in this study preferred financial supports in the form of pay increment to any other form of support. This might be argued that other forms of financial support such as allowance, bonus, compensation, or other forms of subsidy are not as effective as cash. Again, wage increment would help public employees to deal with the high cost of living conditions in Cambodia as well as to acquire and fulfill various needs. 
Based on the above findings, financial support seems to be the most valued by public employees. They were not likely to be satisfied with the absence of financial support. This might be due to the fact that public salary is not enough to support living costs of those who currently served the public service. Thus, it can be argued that this unsatisfied need may drive the employee to state that a satisfying wage is the first factor that motivates them to exert more effort in their jobs. This is supported by Latham and Ernst (2006), who indicated that employee work motivation should be implemented according to Maslow's hierarchy needs. Where five needs are ranked in a hierarchical order from the lowest to the highest, and human basic needs must be fulfilled and satisfied before achieving the next level of work motivation.

However, to some extents, it would be challenging to introduce substantial financial support in the public sector particularly in Cambodia due to strict public policy, government regulation and public financial constraints. Similar findings has been indicated by Wittmer's (1991) work that there are more obstacles to providing more financial incentives particularly to linking pay with performance in the public sector organizations. There are many reasons behind those ideas; limited public budget, strict job classification and government regulation might be reasons that limit and tightly structure the pay system. This may constrain and prohibit the use of financial incentives to motivate public employees. On the other hand, strong union power may also prohibit wage gains to all public employees.

\section{(Non-Financial Support)}

Even though financial support appears to be the most important motivational factor, we have found non-financial supports particularly organizational supports and job related characteristic supports were found to be the second most important factor of employee motivation. It is so because one of the key objectives of providing nonfinancial support is to encourage and motivate any single behaviour that is beyond expectations, regardless of whether the behaviour is different, complicated, extraordinary or not. As mentioned by many motivation theories in the literature review, besides material supports, employees need psychological and emotional supports that can be met by non-financial incentives. And non-financial incentives offer countless benefits to both employees and organizations. This is also supported by many motivation theories that beside material needs, people need psychological 
needs that can be fulfilled by various ways of non-financial incentives. In regard to motivation theories, Maslow's Hierarchy of Needs theory has emphasized that selfesteem and self-actualization needs are the higher level of needs, which could be fulfilled by non-financial incentives (Lathan \& Ernst, 2006). Moreover, one of the noticeable benefits is to fulfill public employees' needs and motivation without effecting government budget.

In addition to the findings of non-financial supports, some research participants asserted that their management did not always recognize the efforts as well as the contribution of employees. The result also revealed that some respondents would appreciate a supportive and cooperative working environment, positive, and constructive feedback, appreciation and recognition from their supervisors. Receiving a feeling of care and concern, personal feedback for work well-done from the employer or a co-worker, could maintain the employees in a positive thinking way about their work and workplace. Furthermore, it could encourage employees to perform better and go an extra mile to achieve individual and organizational goals. Furthermore, non-financial incentives do not directly deal with cash or payment and they can be tangible and intangible (Assaf, 1999; Bunchan, Thompson \& O'May, 2000). Some examples of this type of incentives are: motivating employee to exert more effort by providing them with flexible working hours, more job responsibility and autonomy, enabling more opportunities for capacity development and self advancement, allowing them to use a variety of knowledge and skills, creating more opportunities for promotion, recognition and appreciation of employees' effort and accomplishment through verbal and written appreciation, encouraging employees to participate in decision-making, improving working condition, enabling good working environment, organizing various events or activities in the workplace and so on. According to this, the detail of non-financial supports will be discussed under the two key aspects: (1) job related characteristic supports and (2) workplace supports.

\section{(Job Related Characteristic Support)}

In regard to job related characteristic supports, some research participants expressed a significant aspect of the job that have a potential effect on employee motivation and job satisfaction. Among those were opportunity development and advancement, job autonomy, employee participation and involvement and job responsibilities. It was also found that some respondents in this research were not fully satisfied with 
how their organization tried to motivate them. This means that there is still an opportunity to boost performance and the quality of work and better to motivate employees. What further supports this is that most of the respondents in this research study would do a better job if better motivation existed. On one hand, it is important for an organization to take care of their employees in a manner that they feel appreciated for their knowledge and skills and that they take an interest in their individual careers and try to help them to promote and enhance their capacity within the organization. These activities can be provided through employees' capacity development programmes such as training, education, and so on.

In addition to the activities to enhance employees' capacity, training and professional development are essential motivational determinants, as they nurture personal objective of employees and their value system. In fact, training as a tool of human resource development and management serves many purposes: it can help employees to deal successfully with their job, enable employees to take more responsibility, duties and might be more positions. Moreover, it can assist to achieve their personal goals of professional development as well as career advancement. In the Cambodian context, career opportunities in the public sector are sometimes rigid and scarce; therefore, workplace supervisors or leaders can seek possible ways to replace the existing capacity development and career advancement framework. This activity can be achieved by allowing subordinate staff to present at the division or department meetings, attend workshops and conferences, and gain vital experience and selfconfidence. In addition, properly and fairly selecting public employees for project secondment as well as capacity development programmes inside and outside the national boundary.

Taking about "unchallenging work", participants mostly mentioned taking routine job and repeating daily activities instead of applying new skills and knowledge with challenging work. However, some participants expressed some thoughts about having duties and responsibilities for the current job, positive feeling and getting a lot of self-motivation from the work, new projects and seeing the fruitful result from their efforts. These seemingly contradict the above results as the the research participants came from different departments, and those departments are different in terms of amount of work, duty, responsibility as well as their function and operation. 
Therefore, those comments from research participants may represent only their department.

With regards to "job autonomy", the employees seemed to have more autonomy about how to implement their job than when to do their jobs and when to finish it. Based on the results of this research, work autonomy was still limited compared to other job characteristics in the workplace. From the review of literature the availability of five factors, namely variety of task, identity of task, significance of task, autonomy and feedback could lead to greater employee motivation and job satisfaction (Hackman \& Oldham, 1980). In this regard, the level of motivation that the employees receive from the level of these incentives might not be high in the workplace.

In the sense of "employee participation and involvement", this research indicated that public events and social activities among the group of people within the organization such as fundraising events, sport activities, celebration, parties and so on. May benefit from developing and strengthening the motivational approach of public employees by creating a good feeling toward work and workplace. In addition, it may help to enhance the positive working environment of the organization. It is also important that the organization try to maintain their employees by allowing them to take part in the decision-making, to participate in various public events or provide an opportunity for employees to utilize their acquired knowledge and skills. Providing additional incentive for engagement is essential, it could ensure the sustainability and effective operation of the organization.

\section{(Workplace Support)}

In addition to receiving non-financial support in the form of job autonomy, public employees expected organizational cognition and demonstrations for their sustainability contributions and accomplishments. Both demonstrations and recognitions could be provided in the form of work and workplace supports such as a flexible working environment, capacity development programmes, employee engagement and participations. The content of workplace support was significantly expressed by research participants, in that it included reward and recognition for employees' contribution and good performance, support for flexible working arrangements, conditions and overall environment, the communication and/or 
interaction between employees and employees, and between employees and management within the organization. More specifically workplace support is needed to make public employees feel they are fully supported by their workplace.

Workplace support or organizational support seems to be the most developed in striving for greater performance. That could be because it provides the most visibility, bringing public reward and recognition to the individual and group of employees within an organization. This also consequently led to value increase and organizational reputation enhancement. However, the result shows that workplace support in the form of performance recognition was the most neglected area of nonfinancial incentives for employee encouragement and motivation programme. It is essential to recognize and reward employees for their contributions and achievements in any change performance and working effort. The findings in this research could not come to a satisfactory assumption with regard to the extent to which non-financial incentives in the form of organizational demonstrations and recognition are linked to employees' work performance at present. Therefore, organizations could further improve the recognition area by strategically choosing some activities that are positive and productive for both employees and employers. Furthermore, special attention should be paid to selecting actions with long-term effect, even if they would provide less publicity outside the organization. It is likely that such activities could be understood and appreciated by the public employees, and it should have a positive influence on employee motivational process.

The findings of this research suggested that workplace support was classified into three distinct categories: management support, co-worker support and operational support.

In the case of management support, greater awareness among managers is needed in association with their role as an organizational leader. It is essential to acknowledge that a good manager has more than a single rule in the context of human resource management, it is a fundamental and a cross-cutting function interconnection with performance and management styles including supervision, recognition and feedback. The findings of this study indicated that most employees commented on their performance and contributions were not rewarded and recognized. It might be argued that this negative behaviour can develop a gap between subordinates and 
superiors within the organization. In general practice, this gap may be decreased or eliminated through non-financial incentives.

Recognition usually pertains to both informal and formal intangible incentives that provide praise and show appreciations toward contribution and effort of employees. Recognition always has a positive connotation and it acknowledges good action and behaviour. For example, recognition of good performances, recognition of employees' positive behaviours, successes or employees' contributions are very important and have a great impact on the overall performance as well as the effective operation of an organization. In addition to this, recognition motivates the employees to repeat those positive behaviours and best performances. In addition, it makes the employees feel valuable, and helps to distinguish who is doing a good job and who is not in the workplace. Thus, non-financial incentives are valuable resources of recognition that could be provided to the public employees without cost. In this regard, it is important to introduce and implement job recognition widely in public organizations.

Most of the subordinate staff expressed that they did not receive formal or informal appreciation from their management for their extra time, efforts and contributions to the organization. This may suggest that in some contexts the management did not recognize the effort, contribution as well as the accomplishment of employees. In general practices, superiors do recognize the high importance to non-financial incentives as the factor that increases employees' willingness to exert more time and effort in their jobs. However, they not seem to apply this idea in the workplace. These contradicting behaviours might be steered from individual characteristic of the management and their possible fear of affecting or harming the formal authority relationship with their employees. Moreover, there is no mechanism of job recognition in the public organization such as newsletter or bulletin board to announce higher performance or great achievement of employees neither do they offer a certificate of appreciation other than in very unusual occasions. It also does not have employee job recognition, which is commonly used by Cambodian public organizations to officially announce best performance employees to the rest of public employees in the organization. It is uncertain if the management may be 
uncomfortable or having some difficulties in officially showing recognition such as appreciation for the greater effort and contribution of public employees.

With the identification of "autocratic management style", the research participants emphasized psychological and emotional impediments. Both psychological and emotional impediments represent management behaviour, the way of doing things, which adversely impact the psychological and emotional state of employees in the workplace. These negative aspects of management are similar to "relationship oriented" or "connection oriented" management behaviour and are the common focus of most management support research in the research study of leadership of Amabile, Schatzel, Moneta and Kramer (2004). They had also indicated that the low frequency or the absence of positive management behaviour is a one sided approach as negative management behaviour may affect employees work behavior differently from an absence of positive management behaviour. Furthermore, in the qualitative study on the effect of negative management behaviour on creative acts, they concluded that negative management behaviour is extremely essential and might be more essential than positive management behaviour in affecting employee work performance. Interestingly, even though autocratic management style in the form of negative management behaviour dominated the main theme of insufficient management supports nonetheless positive management behaviour appeared as a sub-theme. Of course, the work behaviour of pubic employees who worked with positive management behaviour were somehow different from those who worked with negative management behaviour. The presence of the positive and negative management behaviour may be due to the fact that research participants working under different managements and/or coming from different departments. Together, the findings on management styles and behaviour regardless of positive or negative behaviour could affect the overall work behaviour of public employees in different ways and this is supported by the study of Amabile, Schatzel, Moneta and Kramer (2004).

On the other hand, it is essential for organizations to treat their employees equally and fairly regardless of age, gender and position. By doing this, employees will feel that they are working in a fair and transparent environment and their contributions are useful for the organization. Adams (1963) in the literature review addresses that in order to satisfy employees, it is essential to ensure that equity and fairness exist 
among the employees in the workplace. Education, skills, experiences, job qualification and so on are the input to the job by every employee. The outcomes the employees receive from their job are pay, reward, benefits and other intrinsic motivations. People want to be treated equally and fairly. If a person's perceived input and outcome are balanced it could determine satisfaction. In other words, when people perceive their input-outcome balance is favorable, and equity exists among employees and satisfaction will be the end result.

Feedback is the way that managers or organizational leaders continuously recognize and shape employee performance. When feedback is done appropriately, it motivates employees and enhances their performances. In contrast, when feedback is poorly carried out it could discourage and demotivate employees, and lastly achieve adverse results. Feedback can be positive and negative, and both have a great potential effect on overall performance. Positive feedback such as appreciation letters or verbal recognition from management is crucial in terms of employee motivation. My research findings also show that performance feedback, especially positive feedback, were considered a type of reward or recognition, which have great potential to motivate employees more than general ones. Receiving personal feedback for a job well-done from the supervisor or a co-worker encourages the employees to think in a positive way about their work and workplace and also makes them "give an extra mile" to achieve the organizational goals. Thus, organizational leaders should provide feedback in the positive and constructive way, which allows the public employees to accept the comments rather than focusing on negative performance, work problems and using criticism as management feedback (Lazeby, 2008).

On the other hand, feedback does not necessarily have to come from leaders or supervisors; it can be come from co-workers or stakeholders. This has been consistent with Herzberg, Mauser and Snyderman (1959), having a good feeling about the job does not always come from the workplace supervisor or organizational leaders, it may come from co-workers. For example positive or constructive feedback of a co-worker such as appreciation, praise and other forms of appreciation can significantly contribute to job motivation. 
Co-worker support was found to be an important factor of job motivation and was one of the prominent sub-themes of workplace support. Kerr (1983) has indicated that lack of co-worker support as a bad effect in which employees will lower their work effort and limit their involvement, participation and contribution toward work and workplace. The findings of this study has some similar points to the study of Herzberg, Mauser and Snyderman (1959), recognition that produces good feelings about a job does not necessarily have to come from supervisors or leaders, it may come from co-workers. Co-worker support exists in various forms in different circumstances. For instance, sharing expertise and knowledge with other members, working with a sense of teamwork, displaying care and concern, showing respect and consideration toward other co-workers, giving suggestions, providing positive feedback under the form of recognition, and so on. However, my research findings differ from this construct in general practices. According the findings, lack of coworker support was the main drawback in motivating public employees to express their willingness to cooperate and work with other members. Also, insufficient coworker support may lead to absence of challenging behaviour in the workplace, constructive and positive feedback from other employees possibly leads to individualism. Most participant's comments on the low level of co-worker supports were expressed in an attempt to gain a better understanding of the effect of teamwork cooperation as well as the effect of co-worker shirking on the overall employee work effort and the outcome. Participants all agreed that employees' involvement and cooperation could be improved if well-designed incentive mechanisms were in place within an organization.

In terms of operational support, the comments by the research participants on resource constraints and workload pressures suggested it was an ongoing issue of Cambodian public organizations. The comments on resource constraints were largely made by public employees in one department while others mentioned workload pressure with regard to insufficient time to finish their work. The different comments seemed to relate more to the type of job held by these two groups of public employees in different departments. Moreover, workplace atmosphere is an active motivator or plainly a satisfier. What is sure, however is that there is no use trying to motivate high performance, while employees feel comfortable and sometimes frustrated by not having the right quality and quantity of materials or equipment they 
need for their work and workplace. This idea is consistent with Amabile's (1996) all kinds of resources (technical, physical and financial resources) need to be available in the workplace for efficiency and effectiveness of work performance (Amabile, 1996).

Although workload pressures and resource constraints were identified as operational impediments, the empirical study on the relationship between these two factors and employee work efforts has produced inconsistent findings. In a research study conducted by Amabile, Conti, Coon, Lazenby and Herron (1996), resource constraints and workload pressures were found to be related to various forms of employee work effort, while other studies suggested that there is no such correlation (Amabile, 1996; Turnipseed \& Murkison, 2000). In addition, those research studies argued that the inconsistency in the research has been attributed to the possibility that the correlation between workload pressures and resource constraints and the level of employee work effort may be curvilinear. Therefore, while workload pressures and resource constraints might destruct or prevent the possibility, opportunity and ability of public employees to effectively perform their tasks, public employees' perception of these two factors as an operational impediment may depend on the level at which it occurs. Some participants in my study may perceive workload pressures and resource constraints as unchallenging and may contribute to boredom and demotivation. These findings have been consistent with the literature on job characteristics (Hackman \& Oldham, 1980). According to theories of job characteristic, all job characteristics can be used to enrich the job, and the job will be more enriching when employee's utilize their multiple skills and knowledge, instead of repeating and reusing one skill and knowledge over and over again to perform the job. Thus together, these findings confirm the view that resource constraint, workload pressure and insufficient time can affect the employees work effort and lead to demotivation (Amabile, Conti, Coon, Lazenby \& Herron, 1996).

One interesting finding was an unexpected theme: low level of job satisfaction but high commitment for greater performance. The finding indicated that even if the research participants did not receive enough rewards and recognition from the public organization or higher work achievements were not fully recognized, there remains a sense of commitment to their organization. This can be implied that individual commitment to public interest had a greatest impact on decision-making processes 
toward the public service provider. Such a motivation emphasizes the individual's responsibility and willingness toward community service, benefiting the community and devoting themselves to social welfare. Commitment to public means the individual's willingness to serve community service, and their interest on public duties and responsibilities (Perry \& Wise, 1990). Perry and Wise also argue that public service motivation is divided into three types: rational motivation, standard motivation and emotional motivation. The commitment to public interest mentioned here reflects the standard motivation of public service motivation, which includes the willingness to serve the public interest, loyalty and maintaining social justice. Such motivations will significantly highlight individual responsibilities and accountabilities toward government institutions as well as community and society.

This is also supported by the research on public service motivation conducted by Rainey (1997) and Simeone (2004). They state that public motivation is a general altruistic motivation that serves the interests of a community of people, a state, a nation or mankind. It is also a study about public ethic or public service values, and the construct has been referred to as a commitment to public interest, commitment to public good, a sense of duty, responsibility and contribution. It can thus be assumed that some public sector employees perceive public service deliveries as extra things to do for personal interest or self-fulfillment and that it is perceived to affect their level of work effort and motivation. Such public employees could be called loyalty employees of public duty because their performance as well as productivity has no correlation with additional incentives, but the attraction to pubic policy, spirit of selfsacrifice and commitment to public interest are key components in their work motivation. From this point of view, it can also be concluded that commitment to the public had a potential affect on the employees' performance.

On the other hand, if most public employees perceive public sector jobs as intrinsically motivating, more meaningful and more interesting because they are provided various opportunities to serve the community and public interest, then it might help public sector managers or public employers to counteract their inability (public budget and resource constraints) to offer satisfying wages that are more attractive and effective. 


\subsection{SUMMARY OF DISCUSSIONS}

Most of the results obtained from the research show that the more dissatisfied public employees were with respect to the non-availability of incentives, the poorer their performance and the less productive they would be at work. This gap could be fulfilled through different types of incentives such as financial incentives and nonfinancial incentives. In case of financial incentives, substantial comments for financial support were addressed by research participants, and wage increment were most highlighted among other forms of direct financial support. This was also supported by one of the most prominent theories of motivation, Maslow's Hierarchy of Needs theory. People are motivated to satisfy their needs and those needs starting from physiological needs or basic human needs. Based on basic human needs, organizations must provide and support their employees with sufficient benefits that enable them to afford living conditions. The point is that without adequate support especially financial support, people will not be able to devote much time and effort to his or/her organization (Latham \& Ernst, 2006).

To some extent, non-financial incentives are essential in motivating public employees. This might be because one of the objectives of offering non-financial incentives is to encourage any single behaviour that is beyond expectation. As emphasized in the research findings, research participants need emotional and psychological needs, and these needs were addressed differently such as respect, recognition, a feeling of achievement, autonomy, feedback and a meaningful job. In addition to the fulfillment of non-financial incentives, it is important to pay more attention to the issue of perceived inequity and unfairness. All these findings are consistent with the literature of theories of motivation. In Maslow's Hierarchy of Needs theory, esteem and self-actualization needs were addressed as top-level needs that can be fulfilled with various activities of non-financial incentives (Lathan \& Ernts, 2006). Hackman and Oldham (1980) stated that job related characteristic theories could be redesigned through various enrichment processes can positively contribute to employee motivation. Herzberg (1966) also pointed out that the jobs with job-related non-financial incentives have a high motivating power. Meanwhile, Expectancy theory addressed the effect of feedback particularly positive feedback either from superiors or co-workers as important in employee motivation and job satisfaction. More importantly, Equity theory of motivation illustrated that in order to 
satisfy employees, it is essential to ensure that equity exists among the employees in the workplace (Adams, 1963).

Putting all results together, it can be concluded that public employees do suffer from high levels of dissatisfaction and this dissatisfaction is mainly from the nonavailability of both financial and non-financial incentives at work. Providing additional financial and non-financial incentives for them could substantially increase productivity as well as employees' performance. Moreover, public commitment may have important practical implications and interest for further research on public service motivation. 


\section{CHAPTER 6}

\section{CONCLUSION}

\subsection{CONCLUSION}

Based on the results of the study, it is evident that there was an absence of certain types of incentive particularly financial incentives in the selected public organization of Cambodia - CIB/CDC. Meanwhile, the level of utilization or implementation of the non-financial incentives is also inadequate. This research study has shown that Cambodian public employees substantially dissatisfied form the non-availability or inadequacy of both financial and non-financial incentives.

The implication of this finding is that, most employees who are not satisfied with their current public salary might be expected to fill this gap through a desire for financial incentives in their organization. Under the motivational theories, an incentive preference is also significantly related to the determination of potential motivational factors. Public employees of Cambodian organizations are not happy with their current wage level in general and this fact is reflected in their first comments on a satisfactory salary as the most important factor leading to the success and effectiveness of their work. However, this does not mean that the employees are only motivated by financial incentives. According to the analysis of the research findings, non-financial incentives are the second most valued among the research participants. In this sense, it is clear that the public employees in this organization first seek to satisfy their basic need as mentioned in the literature review of Maslow's hierarchy of needs theory. After they have satisfactory financial compensation, they are likely to value non-financial incentives under the form of job-related characteristic supports and organizational supports. In this regard, it can be concluded that this public organization would benefit from financial incentives in the motivation of employees, and from non-financial incentives.

The findings also indicated that a non-financial incentive has a great possibility to motivate employees. The importance of non-financial incentives particularly in the form of rewards and recognition was evident in the review of literature and during the research interview and should not be ignored. In the context of public service motivation, non-financial incentives intrinsically motivate public employees without 
affecting the public financial budget. It is believed that if employees are paid substantially, extra financial support such as money is not a key motivator for greater performance. While, receiving additional non-financial incentives such as recognition, approval and praise for the employee contributions, enhancing capacity, skills and knowledge of employee through education and various training programmes, increasing the feeling of empowerment and participation, as well as enabling a good working environment, might be regarded as more effective.

In addition, it would be challenging to introduce substantial financial support in the public sector particularly in Cambodia due to public financial constraints. Thus, it can be supported that the implementation of non-financial incentives would be more realistic in motivating employees in the public sector of Cambodia. While nonfinancial incentives are not effective as a substitute for an inadequate public salary and other financial support, they are essential to fulfill and satisfy public employees' many other needs. Non-financial incentives are essential means of recognizing any single participation, accomplishment and contribution of employees.

Among the non-financial incentives, job-related support and organizational support are preferred as the incentives that would increase the pubic employees' interest in their work and workplace. This means that the public employees in the Cambodian public organization value meaningful jobs with more opportunities for promotion, more responsibility, more flexible working hours, variety of tasks and opportunity to use a variety of skills and knowledge. Enabling more opportunities for participation or involvement in decision-making processes are also good examples of job related support. In this regard, subordinate staff and superiors could be encouraged to participat in decision-making and make any suggestion through the establishment of formal means such as regular meetings, discussion or other mechanisms such as employees' feedback in the organization.

From the above mentioned points, it is essential to emphasize the fact that the success of non-financial incentives based on many variables, and the implementation of non-financial incentives in the public organization does not necessarily mean that they always lead to effectively motivated employees and as a result improve performance of the employees. But it can be proposed that if the job-related non- 
financial incentives as well as other necessary factors are met, non-financial incentives have a great potential to positively affect the employees' motivation. This choice can be identified as those public employees are likely to be intrinsically motivated as mentioned in the review of literature.

On the other hand, this intrinsic motivation is important in promoting and satisfying the needs of an employee. It encourages employees to have positive feelings toward their job, therefore, they will exert more time and effort for better performance without needing any external incentive. In addition, efforts to enhance public employee motivation must protect, promote and build upon the possibility and availability of resources in relation to the organizational goals. A part of this can be implemented through strengthening the efficacy of employees, ensuring the possibility and availability of support as well as the provision of adequate working conditions that enable them to carry out their work appropriately and successfully. It is also important to focus on a culture of support and supervision, to institutionalize recognition of employee achievement, to allocate training and development opportunities in a fair and transparent manner, to fulfill employees' needs for learning and acquiring new skills and new knowledge. This series of actions will require changes in individual characteristics and organizational culture in order to improve the motivational processes and working environment.

Overall, it is therefore logical that the incentive type that the public employees in the organization value most is financial incentives specifically wage or salary increments; meanwhile, non-financial incentives are ranked the second most valued among the public employees. Non-financial incentives could encourage the willingness of Cambodian public employees to exert more effort in their jobs, to work harder, to go beyond the usual performance and to contribute effectively to the organizational goals.

\subsection{CONTRIBUTIONS OF THE STUDY}

The findings of this research make several contributions to understanding the importance of employee incentives, and the effect on work performance. Both components of financial and non-financial incentives are important and have become a key determinant of job satisfaction among public employees particularly in the 
context of Cambodia. The findings of this study provide concrete evidence of pay and non-pay satisfaction dimensions, including satisfaction with availability of certain incentives to motivate public employees for better work performance.

These findings also add value to the study of organizational behaviour including leadership behaviour, culture and justice. In addition, it could assist other scholars, and researchers in their effort to find the way to improve workforce performance in the context of motivation. By pointing out the strength and weakness of current incentive structures and approaches, new motivational strategies can be designed and applied to cover the needs of the entire workforce.

Human resource management could also use the findings of this research study to better understand employee survey results as well as to evaluate the overall performance of employees for work improvement. By identifying the individuals and groups within the organizations that have low productivity, they could also enhance the recruitment and selection process based on the research findings.

The findings of this research also indicated some important points that constitute a challenging and interesting job-related factor for organizational leaders to consider. By doing so, the maximum potential in each employee can be achieved and on the whole increase employee work performance and improve the entire organization.

\subsection{IMPLICATIONS FOR PUBLIC SECTOR MANAGEMENT}

The findings of this research have important implications for various organizations as well as human resource management in Cambodia and wherever the social, political, economic conditions are similar especially in the way they design their incentive programmes. In general, certain types of incentives are offered to recognize and reward a particular performance of public employees while some are offered just to enhance the psychological and moral effect of the employee. In this regard, it may be required to establish some performance criteria to recognize and reward more specific needs of incentives to the public employees.

From the research findings, it is important for public managers to recognize that incentives especially financial incentives are a distinct element of financial benefit, 
and public sector employees may form a specific perception towards those benefits and might perceive different levels of satisfaction with it. Similarly, public employees perceive intrinsically motivating job-related characteristics, positive and negative behaviorus of leaders or workplace supervisors, and positive co-worker behaviour as the most important determinants of employees' work motivation and job satisfaction. The practical implications of this finding are that by improving these variables, public organizations might encourage and motivate public employees to exert more work effort, enhance performance and increase productivity in the organization.

Furthermore, when designing as well as implementing incentives, the organizations should not only focus on the amount of incentive, particularly financial factors, but also ensure that employees perceive the work and workplace related factors which are commonly known as non-financial incentives, because both financial and nonfinancial incentives have a great potential effect toward performance and productivity of the employee as well as the organization.

\subsection{LIMITATIONS AND FUTURE RESEARCH DIRECTION}

It is possible to acknowledge some limitations of this research. The research was only able to examine the importance of employee incentives in general, and more specific work performance. The responses of research participants may have been influenced by some social and economic desirability. Since all participants were only low-level staff not including senior public employees they may have some limitations or not fully understand the entire work procedure and policy of public organizations. Therefore, their responses represent only their part of the entire organization and might have led to biases in some aspects.

Another limitation of this research study is the small sample size relative to the case of Cambodian Investment Board under the Council for the Development of Cambodia - CIB/CDC. The small size of the sample in associated with the selection of a single Cambodian public organization as a case study may lead to some limitations of research findings. The focus of the research study only on the low level employees, excluding middle and senior staff in the organization, therefore, it limits 
diversity in the types of occupations represented, participant demographics and reported levels of work effort, level of work motivation and job satisfaction.

Another limitation of the research relates to the use of in-depth individual interviews to obtain the data. This process raises the significant concern as to whether the interview questions were understood in the same way by all research participants. This issue is commonly one of the key concerns among research participants who have a low level of education and have a limited understanding with research topics and questions. The researcher tried to minimize this potential limitation by using the Cambodian language during each interview. In addition, in order to simplify research questions and where appropriate or necessary, the question and discussion prompts were repeated or rephrased.

Future research might select more than one public organization with diversity of research participants (low, middle and senior staff) in an attempt to obtain enriched information, data, more widely representative of Cambodian public organizations. More particularly, this subject may be required for further investigation in other Cambodian public organizations to understand the motivational process as well as to better understand the motivating potential of the financial and non-financial incentives in the Cambodian public sector. Future research should include both quantitative and qualitative methods to obtain in-depth views around motivation (rewarding and recognition), job satisfaction and performance.

In addition, if possible, the future research may select more than one country, for example, countries that differ on a range of social, economic and cultural dimensions. The fact is that if all research participants came from the one sector and one country it would limit the research findings and might make it impossible to generalize about public organizations. On the other hand, the different social and cultural aspects of each country may add value to the future research of incentives on public employees under different social, economic and cultural contexts.

The results of future research may also be compared to the results of the research from businesses or profit-oriented organizations in which the employees are familiar with implementations and contributions of both financial and non-financial incentives for their work and workplace. 
Moreover, one of the greatest requirements for research attention involves the workforce performance measurement in a typical public service organization in Cambodia. A larger scale for future research should be conducted in different public organizations in an attempt to determine the incentive system as well as incentive preference among public employees and to compare them with any significant preferences in regard to working position, age, gender, knowledge and experience. Further, the incentive preferences of Cambodian public sector employees might be compared to those of Cambodian private sector employees to determine the similarities and differences 


\section{REFERENCES}

Adams, O. \& Hicks, V. (2000). The effect economic and policy incentives on provider practice: Summary of country case studies using a WHO framework. 2000. Geneva: World Health Organization. In Press.

Adams, J.S (1963). "Toward and understanding of inequity", Journal of Abnormal and Social Psychology, 67(1), 422-430.

Aderson, K., Burkhauser, R. \& Raymond, J. (1993). The effect of creaming on placement rates under the job training partnership act, Ind. Lab. Relat. Rev. 46, 613-625.

Akaili, O. (1996). Workforce Management. Amman: Dar Zahran

Alonso, P. \& Lewis, G. (2001) "Public Service Motivation and Job Performance:

Evidence from the Federal Sector" The American Review of Public Administration, 31(4), 363-380.

Alwabel, A. (2005). The role of financial and moral incentives on raising performance level of employee from the viewpoint of the security officer involved in the pilgrimage season. Master Thesis. Naif Arab University for Security Sciences. Riyadh, Saudi Arabia.

Al-Harthi, D. (1999). Raising the efficiency of worker and relationship with financial and moral incentive: Case study on the Civil Defense Personnel in Riyadh. Master Thesis. Naif Arab Academy for Security Sciences. Riyadh, Saudi Arabia.

Amabile, T. M., Conti, R., Coon, H., Lazenby, J., \& Herron, M. (1996). Assessing the work environment for creativity. Academy of Management Journal, 39(5), 1154- 1184.

Amabile, T. M. (1996). Managing for creativity. Harvard Business School Case 396271. In W. A. Sahlman, H. H. Stevenson, M. J. Roberts \& A. Bhide (Eds.), The Entrepreneurial Venture. (2 ${ }^{\text {nd }}$ ed., pp. 521-536). Boston MA: Harvard Business Press.

Amabile, T. M., Schatzel, E. A., Moneta, G. B., \& Kramer, S.J. (2004). Leader behaviors and the work environment for creativity: Perceived leader support. The Leadership Quarterly, 15, 5-32.

Antomioni, D. (1999). "What motivates middle managers"? Industrial Management, 41(6), 27-30.

Angari, A. (1999). Incentive system and their role in raising the level of performance of employees: case study on worker in the Emirate of Riyadh Region. Master Thesis. Naif Arab Acedemy for Security Science. Riyadh, Saudi Arabia. 
Assaf, A. (1999). Managerial behavior in contemporary organizations. Amman: Dar Zahran.

Atkinson, J.W \& Feather, N.T (1966). A theory of achievement motivation. New York, Wiley.

Banjoko, S. (2006). Managing corporate reward systems. Lagos: Pumark Nigeria Limited.

Baker, G.P, Jensen, M.C \& Murphy, K.J (1988). "Compensation and Incentive: Practice vs. Theory" The Journal of Finance, 13, 357-375.

Benh, R. (1995). "The Big Question of Public Management", Public Administration Review, 55(4), 313-324.

Besley, Timothy \& Case, A. (1995). Does electoral accountability affect economic policy choices? Evidence from gubernatorial term limits. The Quarterly Journal of Economics, 110(3), 769-798

Bowditch, James, L., Buono \& Anthony F (1997) A primer on organization behavior, John Wiley \& Son, Inc., United States. ISBN: 0-471-16006-7.

Boyle, G. (2007). Do financial incentives affect the quality of expert performance? Evidence from the Racetrack. NZ institute for the Study of Competition and Regulation, Victoria University of Wellington.

Bright, L. (2008). Does Public Service Motivation Really Make a Different on the Job Satisfaction and Turnover Intention of Public Employees? The American Review of Public Administration, 38(2), 149-166.

Brewer, G.A \& Selden, S. C. (1998). Whistle blowers in the federal civil service: New evidence of the public service ethic. Journal of Public Administration Research and Theory, 8(3), 314-440.

Buchan, J., Thompson, M. \& O'May, F. (2000). Incentive and remuneration in health care: a research review. In press.

Burgess, S. \& Ratto, M. (2003). The role of incentive in the public sector: Issues and evidence. Leverhulme Center for Market and Public Organization, University of Bristol.

Calder, B. J. \& Staw, B. M. (1975). Self-perception of intrinsic and extrinsic motivation, Journal of Personality and Social Psychology, 31(1), 599-605.

Cadsby, C.B., Song, F., Tapon, F. (2007). Sorting and incentive effects of pay-forperformance: Summary of an experimental study. Academy of Management Journal, 50(6), 387-405.

Chiang, F.F.T \& Birtch, T. A. (2005). "A taxonomy of reward preference: Examining country differences" Journal of International Management (11) 
593-375.

Courty, P. \& Marschke (1997). Measuring government performance: Lesson from a Federal Job Training Program, American Economic Review, 87, 383-388.

Collins, A., Tinkew, J. B., Burkhauser, M. (2008). Using incentive to Increase Participation in Out-of-School Time Program. Practitioner Insights, 25.

Crewson, P. (1997). "Public Service Motivation: Building Empirical Evidence of Incidence and Effect", Journal of Public Administration, 4(2), 80-89.

Cragg, M. (1997). Performance incentives in the public sector: Evidence from the job training partnership Act, Journal of Law, Economic and Organization, 13, 147-168.

Culpepper, W. L. (2009). Incentive pay eligibility varies by job and location. Retrieved April 20, 2012 http://www.shrm.org/hrdisciplines/ compensation/ Articles/Pages/IncentiveEligibility.aspx.

Davis, J. H., Schoorman, F. D. \& Donaldson, L. (1997). “ Toward stewardship theory of management" Academic of Management Review, 22 (1) 20-47.

De Cenzo, David A., Robbins \& Stephen P. (1996). Human Resource Management, John Wiley \& Sons, Inc., New York.

Deci, E. L., Koestner, R., \& Rayan R. H. (1999). A meta-analytic review of experiment examing the effects of intrinsic rewards on intrinsic motivation. Psychological Bulletin, 125, 627-668.

Deci, E. L. \& Ryan, R. M. (1985). Intrinsic Motivation and Self Determination in Human Behavior, New York: Plenum Press.

Delfgaauw, J. \& Dur, R. (2002). From public monopsony to competitive market: More efficiency but higher prices, Tinbergen Institute Discussion Paper 1, 02118.

Dixit, A. (2002). Incentive and Organization in Public Sector: An International Review, Journal of Human Resource, 37(4), 696-727.

Dubrin \& Adrew, J. (2002). Fundamental of organization behavior. Thomson Learning South Western, Ohio. ISBN: 0-324-02281-6.

Edwards, J., Caplan, R., \& Harrison, R. (1999). Person-environment fit theory: concpeptual foundations, empirical evidence, and directions for future research. In

Greenberg, J. \& Baron, A.R. (2003) Behaviour in Organization. Prentice Hall, 8, 188-215. 
Epley, N. \& Gilovich, T. (2005). When effortful thinking influence and incentives judgmental anchoring: differential effects of forewarning and incentive on selfgenerated and externally provided anchors. Journal of Behavioral Decision Making. 18, 199-212.

Francois, P. (2000). Public Service Motivation as an Argument for Government Provision, Journal of Public Economics, 78(3), 275-299.

Franco, L.M., Bennett, S., Kanfer, R., \& Stubblebine, P. (2004). Detrminanats and consequences of health worker motivation in hospital in Jordan and Georgia. Soc.Sci.Med., 58(2), 345-355.

Genebra, P. (2003). "A New Face for Private Providers in Developing Countries: What Implications For Public Health", Bulletin of World Health Organization, 81(4), Unspecified pages.

Ghauri, P. (2005). Research Methods in Business Studies, A Practical Guide, Prentice Hall, England.

Glazer, A. (2004). Motivating devoted workers, International Journal of Industrial Organization, 22(3), 427-440.

Hackman, J. R \& Oldham, G. R. (1980). Work redesign. Menlo Park, CA: AddisonWesley Publishing Company.

Hartman, R. J., Kurtz, E. M., Moser, E. K. (1994). Incentive program to improve transit employee performance, National Academic Press, Washington, D.C.

Hackman, J. R \& Oldham, G. R (1976). "Motivation through design of work: Test and Theory", Organization Behavior and Human Performance, 16(1), 250279.

Hackman, J. \& Lawler, E. (1971). "Employee Reaction to Job Characteristic." Journal of Applied Psychology Monograph. 55, 259.

Harvey, S. J. (2005). "Why did you do that? An economic examination of the effect of extrinsic compensation on intrinsic motivation and performance" Journal of Economic Psychology, 26, 549-566.

Hergzberg, F. (1966). Work and the nature of man. Cleveland: World Publishing.

Heery, E. (1996). “ Risk, representation and the new pay”. Personnel Review, 25(6), 54-65.

Helepota, H. A. (2005). "Motivational theories and their application in construction", Cost Engineering, 43(3), 14-35.

Heckman, J., Smith, J. \& Taber, C. (1996). "What do bureaucrats do? The effects of performance standard and bureaucratic preferences on acceptance into the JTPA Program”, NBER Working Paper 5535. 
Houston, D. J (2000). Public-service motivation: A multivariate test. Journal of Public Administration Research \& Theory, 10(4), 713-28.

Jadallah, M. (1997). The impact of incentives in raising the efficiency of workers. Management Development, 56(51), 34-46.

Johnson, P. M. (2005). A glossary of political economy terms. Retrieved July 10, 2012 from http://www.auburn.edu/johnspm/gloss/incentive.

Jones, Ben \& Olken, B. (2005). Do leader matter? National leadership and growth since world war II, Quarterly Journal of Economic, 120(3), 835-864.

Jurkiewicz, C., Masey, T. \& Brown, R. (1998). "Motivation in Public and Private Organization: A Company Study", Public Productivity and Management Review, 21(3), 230-250.

Judge, T.A, Thoresen, C. J, Bono, J. B. \& Patton, G. K. (2001). "The Job Satisfaction -Job Performance Relationship: A Qualitative and Quantitative Review", Psychological Bulletin, 127(3), 376-407.

Kasser, T. (2000). I-D compensation theory and intrinsic / extrinsic goals. American Psychologist, 55, 224-226.

Kahn, C. M, Silva, E. C. D. \& Ziliak, J. P. (2001). Performance based wages in tax collection: The Brazilain tax collection reform and its effects. Economic Journal, 111(468), 188-205.

Kamoche, K. (1997). "Competence-creation in the African Public Sector". International Journal of Public Sector Management, 10(4), 268-278.

Kasser, T., \& Rayan, R. M. (1996). Further examining the American dream: Differential correlates of intrinsic and extrinsic goals. Public Productivity and Management Review. 21, 230-50.

Kerr, N. L. (1983). Motivation losses in small groups: A social dilemma analysis. Journal of Personality and Social Psychology, 45(4), 819-828.

Kim, S. M. (2005). "Individual-level Factors and Organizational Performance in Government Organizations", Journal of Public Administration Research and Theory, 15(2)245-61.

King, N. (2004a). Using interviews in qualitative research. In C. Cassell \& G. Symon (Eds.), Essential Guide to Qualitative Method in Organizational Research. (pp.11-22). London; Thousand Oaks: Sage Publication.

King, N. (2004b). Using templates in the thematic analysis of text. In C. Cassell \& G. Symon (Eds.), Essential Guide to Qualitative Method in Organizational Research. (pp. 256-270). London: Sage Publications. 
Komaki, J. (1982). Managerial effectiveness: Potential contributions of the behavioral approach, Journal of Organizational Behavior Management, 3, 7183.

Kumari, G. \& Pandey, K. M. (2001). Job Satisfaction in Public Sector and Private Sector: A Comparison. International Journal of Innovation, Management and Technology, 2(3) 1-7.

Lazenby, S. (2008). How to motivate employees: What research is telling us. Public Management, 90(8), 1-5.

Latham, G. P. (2007). Work motivation: history, theory, research and practice. Sage Publications, Inc.

Latham, G. P. \& Ernst, C. T. (2006). Keys to motivating tomorrow's workforce. Human Resource Management Review, 16, 181-198.

Lawler, E. E. \& Jenkins, G. D. (1992). "Strategic rewards systems", Handbook of Industrial and Organizational Psychology, $2^{\text {nd }}$ ed. Vol. 3.

Lawler, E. E. (2000). Rewarding excellence: Pay strategic for the new economy. San Francisco: Jossey-Bass Publishers.

Lawler, E. E. (1973). Motivation in work organizations, Monterey: Brooks - Cole

Lawler, E. E. (1971). Pay and organizational effectiveness: A psychological view. New York, McGraw-Hill.

Lawler, E. E. (1996). Teams, pay and business strategy: finding the best mix to achieve competitive advantage. American Compensation Association Journal: $12-24$.

Leech, N. L., \& Onwuegbuzie, A. J. (2007). An array of qualitative data analysis tools: A call for data analysis triangulation. School Psychology Quarterly, 22(4), 557-584.

Ledford, G. E. \& Lawler, E. E. (1994). Reward systems that reinforce organizational change. University of Southern California, Los Angles, CA.

Lindner, J. R. (1998). “Understanding employee motivation”, Journal of Extension, $3,1-8$.

Locke, E. A. (1968). "Toward a Theory of Task Motivation and Incentive", Organization Behavior and Human Performance, 3, 157-189.

Lock, E. A. (1976). The nature and cause of job satisfaction, Handbook of Industrial and Organizational Psychology, Chicago: Rand McNally.

Locke, E. A. (1969). What is job satisfaction? Organizational Behavior and Human Performance, 4, 309-336. 
Lock, E. A., \& Latham, G. P. (2004). What should we do about motivation theory? Six recommendations for the twenty-first century. Academy of Management Review, 29(3), 388-403.

Mathauer, I. \& Imhoff, I. (2006). Health worker motivation in Africa: the role of non -financial incentives and human resource management tools, Human Resource for Health, 4(24).

Malhotra, N. K., Hall, J., Shaw, M., \& Crip, M. (1996). Marketing research: An applied orientation. Sydney, NSW: Prentice Hall.

Mathauer, I. \& Imhoff, I. (2006). Health worker motivation in Africa: the role of non-financial incentives and human resource management tools. Human Resource for Health. 4(24) 1-17.

Mager, D. \& Sabilia, J. (2010). Street Smart Sustainability. San Francisco: BerrettKoehler Publisher, Inc.

Mason, J. (2004). Qualitative researching. ( $2^{\text {nd }}$ ed.) London: Sage Publications.

Martocchio, J. (2006). Strategic Compensation: A Human Resource Management Approach, New Jersey: Prentice Hall.

Maslow, A. H. (1943). A theory of human motivation. Psychological Review, 50, 370-396.

Merchant, K. \& Van der Stede, W. (2007). Management control systemsPerformance measurement, Evaluation and Incentives, $2^{\text {nd }}$ ed. Printice-Hall.

McClelland, D. C. (1961) "The Achieving Society". The Management Journal, Princeton: Van Nostrand.

Mitchell, J. (1982). Looking after ourselves: an individual responsibility?. Journal of the Royal Society for Health, 4, 169-173.

Mingers, J. (2001). Combining IS Research Methods: Toward a Pluralist Methodology. Information System Research, 12(3), 247-254.

Morgan, P. \& Baser, H. (2007). Building the Capacity for Managing Public Service Reform: The Tanzania Experience. European Center For Development Policy Management. 57, 1-27.

Morgan, G., \& Smircich, L. (1980). The case of qualitative research. Academy of Management Review, 5(4), 491-500.

Naff, Katherine \& Crum, J. (1999). "Working for America: Does Public Service Motivation Make a Difference?" Review of Public Personnel Administration, 19(4), 5-16. 
O'Leary, Z. (2010). The essential guide to doing your research project. London: Sage Publications Ltd.

Pare, G., Tremblay, M. \& Lalonde, P. (2001). Workforce retention: What Do IT Employees Really Want? SIGCPR 2001, San Diego, CA, USA.

Pawlowski, Suzanne D., Datta, Patrin, Houston \& Andrea L., (2005). “The Gradually Changing Face of State IT Jobs", Communications of the ACM, 48(5).

Perry, J. L. \& Wise, L. R (1990). The motivational based of public service. Public Administration Review, 50(3), 367-373.

Porter, L. W. \& Lawler, E. E. (1968). Managerial attitude and performance, Homewood: Richard D. Irwin.

Rafikul I. \& Ahmad Zaki Hj. (2004). Ranging of employee's reward and recognition approaches: A Malaysian Perspective, A Journal of International Business and Entrepreneurship Development, 2(2), 24-49.

Rainey, H.G (1997). Understanding and managing public organizations: Jossey-Bass Publishers.

Rayan, R. M. \& Deci, E. L. (2000). When rewards compete with nature: The undermining of intrinsic motivaton and self-regulation. In Sansone \& Harackiewicz (2000) Intrinsic and extrinsic motivation: The search for optimal motivation and performance. San Diego: Academic Press, 14-54.

Reilly, P. (2003). "New Approaches in Reward: Their Relevance to the Public Sector", Public Money and Management, 23(4), 245-352.

Rydval, O. \& Ortmann, A. (2004). How financial incentive and cognitive abilities affect task performance in laboratory setting: An illustration. Economic Letters, $85,315-320$.

Samson, D. \& Daft, R. (2002). Management. Pacfic Rim ed. South Melbourne: Vic. Thomson.

Sansone, C. \& Harackiewicz, J. M. (2000). Intrinsic and extrinsic motivation: The search for optimal motivation and performance. San Diego: Academic Press.

Seale, G. (1999). The quality of qualitative research, London: Sage Publications.

Shanks, D.R., Tunney, R.J., \& McCarthy, J.D. (2002). A re-examination of probability matching and rational choice. Journal of Behavioral Decision Making, 15, 233-250.

Skinner, B. F. (1956). "A case history in scientific method", American Psychologist, 11(1), 221-233. 
Smith, P. C., Kendall, L. M. \& Hulin, C. L. (1969). The measurement of satisfaction in work and retirement, Chicago, IL: Rand McNally.

Staats, E. (1988). "Public Service and the Public Interest", Public Administration Review, 48, 601-605.

Steers, R. M. \& Porter, L. W. (1987). Motivaton and work behavior. $4^{\text {th }}$ edition, New York: McGraw-Hill.

Stone, D. N. \& Ziebart, D. A. (1995). A model of financial incentive effects in decision making. Organizational Behavior and Human Decision Processes, 61, 250-261.

Su, X. H. \& Bozeman, B. (2009). Do expectation meet aspiration? The relationship of public manager's job choice motives to job satisfaction. International Review of Public Administration, 14(1) 1-8.

Thorpe, R. \& Homan, G. (2000). Strategic reward system, London, Prentice Hall.

Turnipseed, D., \& Murkison, G. (2000). Good soldiers and their syndrome: Organizational citizenship behavior and the work environment. North American Journal of Psychology, 2(2) 281-303.

UNDP (2006). Incentive Systems: Incentive, Motivation, and Development Performance. A UNDP Capacity Development Resource.

Vroom, V. H. (1964). Work and Motivation, New York: Wiley.

Wittmer, D. (1991). Serving the people or serving for pay: Reward preference among government, hybrid sector, and business managers. Public Productivity and Management Review, 14, 369-383.

Wright, B. E. (2000). "Public sector work motivation: A review of the current literature and a revised conceptual model", Journal of Public Administration Research and Theory, 10(28), 4-15.

Wright, B. E. \& Pandey, S. K. (2008). Public service motivation and the assumption of person-organization fit testing the mediating effect of value congruence. Administration \& Society, 40(5), 502-521.

WorldatWork Press. (2007). Incentive pay: Creating a competitive advantage. Scottsdale, AZ: WorldatWorlk Press.

Yoshikawa, H., Weisner, T. S., Kalil, A., \& Way, N. (2008). Mixing qualitative and quantitative research in developmental science: Uses and methodological choices. Developmental Psychology, 44(2), 344-354.

Young, B. C. (2000). "Method of Motivation: Yesterday and Today" Retrieved October, 04, 2012, from http://www.studymode.com/essays/Methods-OfMotivation-202735.html 
Zurn, P., Dolea, L., \& Stilwell, B. (2005). Nurse retention and recruitment: developing a motivated workforce. Retrieved April 30, 2012. www.icn.ch/global/ issue4Retention.pdf. 


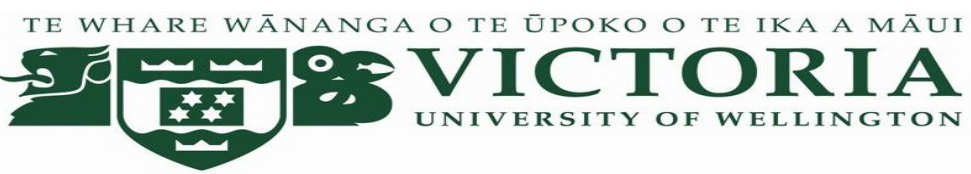

\title{
Organization Letter of Permission
}

\section{Cambodian Investment Board-CIB Council for the Development of Cambodia-CDC}

\author{
Dear Secretary / Deputy Secretary General of Cambodian Investment Board,
}

I am a Master's student at Victoria University of Wellington and I am conducting research on the importance of employee incentives and their effectiveness in improving quality performance in one of Cambodia's public organization, specifivally in the case of Cambodian Investment Board / Council for the Development of Cambodia. I am writing to request your permission to include your organization as a case study. This research is funded by NZAID program and Victoria Management School / Victoria University of Wellington.

This research will be important and useful for your organization as well as your officials. More particularly, the findings of this study could contribute to job satisfaction, quality of work performance, and better working environment within the organization. If you are interested I can send you a summary of my findings or analysis at the completion of my rssearch anticipated to be about March 2013.

If you decide to be part of my study, I would like to conduct interviews with officials from your organization. Eight officials will be purposively selected for an interview. The interview itself will take approximately 60 minutes, and will be scheduled at a time that suits each participant. My research follows all the guidelines and requirements of Victoria University's Pipitea Human Ethics Committee. Participation by the selected officials is completely voluntary and they are free to refuse to take part in the interview at any time, without giving a reason, before data collection is completed in July 15, 2012, and all relevant data or/and information will be destroyed if participants withdraw from this research.

All relevant data or information will be stored in a password-protected file and will be restricted to the researcher and the supervisor only. In addition, all data or information obtained from this research will be retained confidentially, and will be destroyed 2 years after the completion of this study.

I am happy to answer any questions you may have in person or via the contact address below. Alternatively, my supervisor is also available to discuss any questions or issues you may have.

Best regards,

Researcher: Oun Tep

School of Management

Victoria University of Wellington

Phnoe: 0220742045

Email: tepoun@yahoo.com
Supervisor: Prof Lawrence Corbett

School of Management

Victoria University of Wellington

PO Box 600, Wellington

Phone: 044635138

Email :lawrie.corbett@vuw.ac.nz 
RESEARCH PROJECT INFORMATION SHEET

Exploring the Importance of Employee Incentives and their Effectiveness in

Improving Quality Performance

in a Cambodian Public Organization

\section{Dear Participants}

I am conducting research on the importance of employee incentives and their effectiveness in quality performance on the selected Cambodian public organization - Cambodian Investmetn Board / Council for the Development of Cambodia. This research has been approved by Pipitea Human Ethics Committee and will be developed in a form of student thesis in order to fulfill my master's degree in management studies. I realize that this requires a serious commitment of time and effort to participate in my research, but I believe that the findings will be important and useful particularly for you and your organization to improve quality of work performance and hopefully lead to an improved work environment.

In this regards, I would like to carry out an interview with you on the topic around the incentives, their importance, and the effect on work performance. The interview will be conducted over approximately 60 minutes and will be scheduled at a time that suits you. Before you decide whether or not to take part, it is important for you to understand why the research is being done and what it will involve. Please take time to read the following information carefully.

Your participation is completely voluntary. You are free to refuse to take part in the interview at any time, without giving a reason, before data collection is completed in July 15, 2012, and all relevant data or/and information will be destroyed if participants withdraw from this research. If you do decide to participate, you will be given this information sheet to keep and be asked to sign a consent form. Your identity will not be shown on any report findings and any information provided will be kept confidential to the researcher and the supervisor. All recorded and written data will be kept in a locked file at the School of Management of Victoria University of Wellington.

In addition, all electronic data or information will be stored in a password-protected file and will be restricted to the researcher and the supervisor. Also, data or information obtained from this research will be retained confidentially, and will be destroyed 1 years after the project is completed in March 2013.

In addition, the key findings of this research will be presented to concerned parties in a form of verbal or written report requested and the findings may be used in publications as academic output such as journal and academic conference papers in addition to my Master's thesis. 
Thank you very much for your time and help in making this research possible, If you have any queries please phone, email or write to me or my supervisor.

Researcher: Oun Tep

School of Management

Victoria University of Wellington

Phnoe: 0220742045

Email: tepoun@yahoo.com
Supervisor: Prof Lawrence Corbett

School of Management

Victoria University of Wellington

PO Box 600, Wellington

Phone: 044635138

Email :lawrie.corbett@vuw.ac.nz 


\section{Victoria Management School}

\section{RESEARCH PROJECT CONSENT FORM \\ Exploring the Importance of Employee Incentives and their Effectiveness \\ in Improving Quality Performance in a Cambodian Public Organization}

Please confirm your consent to participate in this research by placing a tick in the relevant boxes below:

I have been given an information sheet containing the nature and objectives of this research project and I have understood that information. I have been given an opportunity to ask questions and have them answered to my satisfaction.

I understand that I am free to withdraw from the interview or to decline to answer any particular questions in the study.

I agree to take part in this research project and provide information to the researcher under the conditions of confidentiality.

I agree that my conversation can be audio-recorded.

I understand that I may ask further question at any time.

I understand that a summary of the research findings will be provided at the completion of this study.

Participant

Researcher

Name:

Signature:

Date:

Date: 


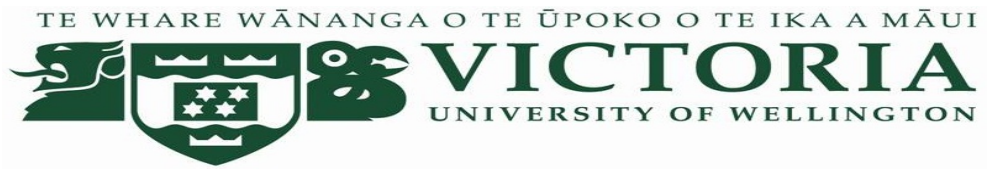

\section{Exploring the Importance of Employee Incentives and their Effectiveness in Improving Quality Performance in a Cambodian Public Organization}

\section{INDICATIVE INTERVIEW QUESTIONS}

1. Could you tell me a little bit about your personal background (Name, position, work experiences and your job included your duty and responsibility).

2. How long have you been working here? And what did you do in the past?

3. How do you think about working environment in the Cambodia public organization in general, and more specific about your organization - Cambodian Investment Board / Council for the Development of Cambodia?

4. Do you satisfy with everything you got so far in terms of financial and / or nonfinancial benefit? Why?

5. What are your requirements and your expectations with your current job? Why ? do you have any intentions to change the job? Why?

6. What is your perception toward employee incentive either financial or nonfinancial incentive within your organization?

7. How do you think about quality of work performance within your organizaion?

8. What do you think about employee incentives? It is available or exist in your organization?

9. How important incentives are for Cambodian public employees in general, and more specific for you? Are there any connections or effects on staff work performance?

10. What type of incentives are best match with your job, your current circumstance as well as your current working evironment?

11. Does incentives always importance or necessary in workplace? Why?

12. How does incentive work or apply effectively in your organization? Are there any associated risks or drawbacks?

13. Are there other ways or alternatives to improve the quality of work performance within your organization? 